\title{
THE ENERGY DEMANDS OF A 2,000 METER RACE SIMULATION FOR NATIONAL LEVEL OARSWOMEN
}

BY

INGRID VICTORIA YOUNG

B.Sc., The University of Waterloo, 1984

A THESIS SUBMITTED IN PARTIAL FULFILLMENT OF THE REQUIREMEN!TS FOR THE DEGREE OF MASTER OF PHYSICAL EDUCATION

IN

THE FACULTY OF GRADUATE STUDIES

School of Physical Education

We accept this thesis as conforming to the required standard

THE UNIVERSITY OF BRITISH COLUMBIA MAY 1988

(c)INGRID VICTORIA YOUNG, 1988 
In presenting this thesis in partial fulfilment of the requirements for an advanced degree at the University of British Columbia, I agree that the Library shall make it freely available for reference and study. I further agree that permission for extensive copying of this thesis for scholarly purposes may be granted by the head of my department or by his or her representatives. It is understood that copying or publication of this thesis for financial gain shall not be allowed without my written permission.

Department of Physical Education

The University of British Columbia Vancouver, Canada

Date Guil 22/88 


\begin{abstract}
THE ENERGY DEMANDS OF A 2,000 METER RACE SIMULATION FOR NATIONAL LEVEL OARSWOMEN.
\end{abstract}

I.V. YOUNG

The purpose of this study was to assess the energy demands of a 2,000 meter race simulation (RS) for national level oarswomen; as evaluated on a rowing ergometer (RE). A Progressive Intensity Test (P.I.T.) was also performed on the RE to further evaluate the RS. Six national level oarswomen ( $\overline{\bar{X}}$ values: age $=24.5$ yrs. $, \mathrm{ht}=179 \mathrm{~cm}, \mathrm{wt}=75$ $\mathrm{kg})$, all current national team candidates (1988), participated in this investigation. A $61 / 2$ minute tape recorded water race was used to execute a 2,000 meter RS on a Dr. Gjessing Ergorow ergometer. The tape recording was an actual race tape that was respliced to last exactly 6 $1 / 2$ minutes. Metabolic and respiratory exchange variables were continuously monitored by an open circuit method, utilizing a Beckman Metabolic Measurement cart interfaced on-line with a Hewlitt Packard 3052A data acquisition system. The energy demands were calculated from metabolic variables, total oxygen cost and the analysis of excess post-exercise oxygen consumption (recovery $\mathrm{VO}_{2}$ ). 
Results indicated a mean $\mathrm{VO}_{2} \max$. of $3.851 . \mathrm{min}^{-1}$, mean net $\mathrm{VO}_{2}$ of $24.48 \mathrm{I}$ and a mean recovery $\mathrm{VO}_{2}$ of $4.92 \mathrm{l}$. This represented the aerobic cost of the event at approximately $80 \%$ or $4 / 5$ ths of the total energy cost while the anaerobic contribution was approximately $20 \%$ of $1 / 5$ th of the total energy cost. During the RS, $\mathrm{VO}_{2}$ values rapidly increased to $90 \%$ of mean $\mathrm{Vo}_{2} \max .\left(3.851 . \mathrm{min}^{-1}\right)$ in the first two minutes. Mean max. $V_{E}$ (BTPS) RS value was $122.41 . \mathrm{min}^{-1}$. $V_{E}$ plateaued after two minutes and remained around $90 \%$ of P.I.T. mean max. $V_{E}$ for the final $41 / 2$ minutes. Mean max. excess $\mathrm{CO}_{2}$ for $\mathrm{RS}$ was 19.81 $\mathrm{ml} . \mathrm{kg}^{-1} \cdot \mathrm{min}^{-1}$. The average maximal heart rate, as recorded in the RS was $192.8 \mathrm{bpm}$. The results of this study indicate the high aerobic demands and tremendous exercise intensity involved in the 2,000 meter RS. 
TABLE OF CONTENTS:

PAGE

ABSTRACT $\ldots \ldots \ldots \ldots \ldots \ldots \ldots \ldots \ldots \ldots \ldots \ldots \ldots \ldots \ldots \ldots \ldots \ldots \ldots \ldots \ldots$

TABLE OF CONTENTS $\ldots \ldots \ldots \ldots \ldots \ldots \ldots \ldots \ldots \ldots$ iv

LIST OF TABLES $\ldots \ldots \ldots \ldots \ldots \ldots \ldots \ldots \ldots \ldots \ldots \ldots \ldots$

LIST OF FIGURES $\ldots \ldots \ldots \ldots \ldots \ldots \ldots \ldots \ldots \ldots \ldots \ldots \ldots \ldots$

ACKNOWLEDGEMENTS $\ldots \ldots \ldots \ldots \ldots \ldots \ldots \ldots \ldots \ldots \ldots \ldots \ldots \ldots \ldots$

CHAPTER ONE - INTRODUCTION \& PROPOSAL ........... I

CHAPTER TWO - REVIEW OF LITERATURE ............ 17

CHAPTER THREE - METHODOLOGY ............. 41

CHAPTER FOUR - RESULTS \& DISCUSSION ........... 49

CHAPTER FIVE - SUMMARY \& RECOMMENDATIONS $\ldots \ldots \ldots .88$

PROGRESSIVE INTENSITY CONSENT FORM ........... 93

RACE SIMULATION CONSENT FORM $\ldots \ldots \ldots \ldots \ldots \ldots \ldots .96$

BIBLIOGRAPHY $\ldots \ldots \ldots \ldots \ldots \ldots \ldots \ldots \ldots \ldots \ldots \ldots \ldots \ldots \ldots$

APPENDIX A - P.I.T. PROTOCOL .............. 104

APPENDIX B - EXERCISE METABOLISM ............. 105

APPENDIX C - TABLE II CALCULATIONS .......... 106

APPENDIX D - STATISTICAL CALCULATIONS ........ 107 
LIST OF TABLES

PAGE

Table I - Physical Characteristics of Subjects .... 51

Table II - Race \& P.I.T. Physiological Parameters ... 52

Table III - Vo 2 Totals fo Race simulation ......... 54 


\section{LIST OF FIGURES}

PAGE

Figure 1 - Absolute $\mathrm{VO}_{2}$ vs Time (Rs) ............ 56 Figure 2 - Relative ${ }^{\circ} \mathrm{VO}_{2} \max$. vs Time (RS) ......... 58 Figure $3-$ HR vs Time (Rs) ..................60 Figure 4 - Mean Excess $\mathrm{CO}_{2}$ vs Time (RS) ..........6 61

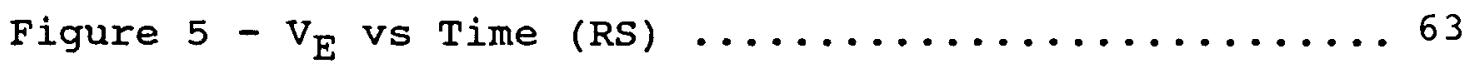

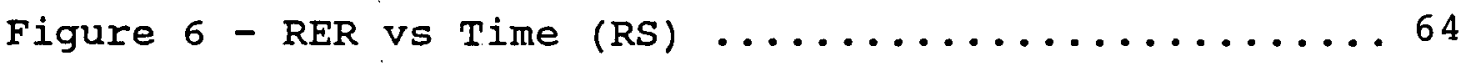
Figure 7 - Blood Lactate (subj.E) vs Time (RS) ......66 Figure 8 - Blood Lactate (subj. B \& E) vs Time (P.I.T.) 67 


\section{ACKNOWLEDGEMENTS}

I would like to thank my graduate and thesis advisor Dr. T.E. Rhodes for his assistance and continued encouragement in the preparation of my thesis. Thank-you to the six oarswomen who offered their time and energy for the execution of this project. Special thanks to Dr. Sue Hopkins for her generosity and assistance.

To Trish, Kathryn and Jessica, thank-you for your unfaultering support and encouragement over this seemingly endless road.

This paper is dedicated to my wonderful family (Mom, Dad, Deb \& Greg) for a lifetime of support and encouragement. 
$-1-$

CHAPTER ONE

INTRODUCTION \&

PROPOSAL 


\section{INTRODUCTION}

The sport of rowing has been recognized internationally since 1893 with the staging of the World Rowing Championships yearly (with a few exceptions). Rowing has been an exclusively male athletic event up until the year 1954 when women were introduced to international competition. It was in this year that women competed in the F.I.S.A. (Federation internationale des societes d'Aviron) Championships for the first time. However, it was not until 1976 that women's rowing events were added to the Olympic Games roster. With the inception of women's rowing to the 1976 olympic Games has come a substantial increased in participation and enthusiasm (CATCH, special issue, summer 1984).

For the first 30 years (1954-1984), women raced over 1,000 meters, one half the 2,000 meter racing distance of their male counterparts. Following the 1984 Olympics at Lake Casetas, Los Angeles, the oarswomen's racing distance was increased to 2,000 meters. With the two fold increase in their racing distance, it is obvious that the physical demands will be altered. As a result, training programs and emphasis must be re-evaluated and adjusted to meet the 2,000 meter racing demands.

There is a very limited supply of information (data) available on the physiological profiles and responses to the demands of the old 1,000 meter race. To the best of 
our knowledge, there is currently no published data on the females responses to the 2,000 meter race ( 6 to 7 minutes maximal rowing). In contrast, there has been quite a substantial volume of data collected on the oarsman's physiological profiles and responses to the 2,000 meter race (5 $1 / 2$ to 6 minutes max. exercise). A combination of the 1,000 meter women's data and the 2,000 meter men's data can assist in the predictions of the oarswomen's physiological adjustments to the 2,000 meter race.

For women to race 2,000 meters in the various boat sizes $(8+, 4+, 2-, 1 x, 2 x, 4 x)$, the race duration will be approximately 6 to 8 minutes. In comparison, the 1,000 meter races, lasted between 3 and 4 minutes. Obviously, a far greater portion of the energy supply will have to be provided by the aerobic system in the 2,000 meter race because of the duration of the event. Furthermore, the longer race will allow for the achievement of a steady state level of oxygen consumption, a state not attainable in the shorter, sprint like 1,000 meter race.

With a greater emphasis being placed on the aerobic energy system more training time must be devoted to the enhancement of this systems efficiency. By evaluating the aerobic and anaerobic energy systems contributions to the 2,000 meter race it should be possible to justify modifications in the females training regimens. At the present time, we have a very accurate method of measuring. the body's total aerobic metabolic rate by determining the 
oxygen uptake during the exercise period. However, superior methods for quantifying the anaerobic energy yield are not currently available (Astrand \& Rodahl, 1977, p.30).Consequently, methods such as calculation of excess post-exercise oxygen consumption or oxygen deficit are used. Under the exercise conditions of this investigation, excess post-exercise oxygen consumption (EPOC) will be the method of choice for predicting the anaerobic energy yield. 
$-5-$

PROPOSAL 


\section{INTRODUCTION :}

In recent years, many studies have examined the physiological demands of rowing for the competitive athlete (Hagerman \& Lee, 1971; Jackson \& Secher, 1976; Mahler; 1984; Mackenzie \& Rhodes, 1982). Most of the literature focuses on oarsmen with only a limited number of studies directed toward oarswomen (Hagerman, 1975; Hagerman, et.al., 1979; Hebbelick, et.al., 1980).

Until the year 1985, women had raced over 1,000 meters while their male counterparts raced 2,000 meters. However, the 1985 racing season began with a race alteration for oarswomen. Presently, oarswomen and oarsmen share the 2,000 meter racing distance and the 1,000 meter race has been eliminated from competition. As a consequence of this alteration, analysis of an oarswoman's response to the energy demands of 2,000 meter racing is necessary. Such an analysis could permit justifiable training modifications.

Previous research on the rowing ergometer (RE) with oarswomen performing a 3-minute maximal test indicates that the relative proportions of aerobic and anaerobic energy contribution were 60-65\% and 30-35\% respectively (Hagerman, et.al., 1978; Hagerman, 1984). Hagerman (1975 \& 1979) reported, in studies with oarsmen, that the aerobic/anaerobic energy contribution costs of a 6 minute RE test were in the range of approximately $70 \%$ aerobic and 
20-30\% anaerobic respectively. Based on these previous findings, it would be expected that the energy requirements of a $61 / 2$ minute race simulation (RS) for oarswomen would require more aerobic and less anaerobic energy contributions than for a 3 minute RE test. Furthermore, the $61 / 2$ minute RS should have an energy cost which closely resembles that of the men's 6-minute ergometer test \{based on Astrand \& Rodahl (1977)\}. Current literature on the female's physiological responses to a 1,000 meter race simulation indicates that there is an insufficient amount of time in the 3-minute exercise for the body to establish a steady state (Hagerman, et.al., 1979 \& Hagerman, 1984). In contrast, as indicated in testing oarsmen over 6-minutes, there is sufficient time in the 2,000 meter race to permit the establishment of a steady state.

The purpose of the present study is to predict the contributions of the aerobic and anaerobic energy systems during a 2,000 meter rowing race for national level oarswomen in an eight oared shell. Determination of the response of the energy systems will be based on physiological measurements made before, during and after a $61 / 2$ minute rowing ergometer race simulation. The results of this study will aid in a better understanding of the requirements of the sport. Furthermore, findings could provide some rationale for training modifications to the current oarswomen's programs. 


\section{PURPOSES:}

a) To determine each individual's maximal aerobic power through the administration of a progressive intensity test (PIT) on the rowing ergometer (Dr. Gjessing, Ergorow).

Results of this procedure enable the researcher to predict the work capacity of national level oarswomen in a 2,000 meter race. The race simulation intensity could then be expressed in relative terms (as a $\%$ of the oarswoman's $\mathrm{VO}_{2}$ max.) after obtaining the maximal oxygen consumption $\left(\mathrm{VO}_{2}\right.$ max.) values for each subject.

b) To determine the aerobic/anaerobic energy systems contributions to a 2,000 meter rowing race in an eight oared shell (8+) with national level (Canadian National Team) oarswomen. These findings would provide information regarding the physiological demands of 2,000 meter racing. Consequently, training program modifications could be proposed that could facilitate performance improvements.

c) To examine the blood lactate profiles of the oarswomen during a 2,000 meter race. These profiles will be developed through serial blood lactate measures taken each minute of the $61 / 2$ minute RS. These results could also provide further metabolic/physiological data to be incorporated into the design of specific aerobic and anaerobic exercise sessions to meet individual/crew training needs.

d) To compare maximum $\mathrm{VO}_{2}, \mathrm{~V}_{\mathrm{E}}, \mathrm{HR}$ and blood lactates of the PIT and the $61 / 2$ minute RS. These comparisons will 
provide an indication of the intensity of the RS.

\section{DELIMITATIONS:}

This study is delimited by:

a) The subject sample size $(n=6)$,

b) The sample type (Canadian National Team candidates),

c) The testing period relative to the oarswomen's training schedule (ie. competitive or transitional phase of program).

\section{LIMITATIONS :}

The results of this study are limited by:

a) The data collection capabilities of the Beckman Metabolic Measurement Cart and the Hewlitt Packard Data Acquisition system interfaced with the Beckman,

b) The race simulation protocol's similarity to an actual 2,000 meter water race,

c) The oarswomen's metabolic responses to the protocols of the study, 


\section{ASSUMPTIONS:}

SIMULATION TEST DURATION:

$61 / 2$ minutes is a viable racing time for an $8+$ rowed by national level oarswomen.

SIMULATION TEST INTENSITY:

The intensity of the simulation race is comparable to that of a 2,000 meter water race in an $8+$.

\section{RECOVERY CURVE}

The excess post-exercise oxygen consumption is representative of the anaerobic energy contribution.

\section{JUSTIFICATION OF THE STUDY:}

The 2,000 meter racing distance is new for women as of the 1985 racing season, therefore, there is no current literature available on oarswomen's responses to 2,000 meter racing (physiological/metabolic). Without any precise information pertaining to the energy demands, training programs may be deficient in certain aspects (ie. not enough aerobic emphasis in the existing training programs). The findings will be valuable to coaches and athletes alike (at the national level) in their understanding and preparation for the 2,000 meter rowing race in an $8+$. This study is justified in that it examines a facet in the performance of national level oarswomen which has not yet been investigated. 


\section{HYPOTHESES:}

1) $80 \%$ or $4 / 5$ ths of the energy required for a 2,000 meter national level women's $8+$ race is contributed by the aerobic energy system.

Rationale:

The rationale for this predicted energy contribution is partially based on the reported findings of Hagerman, et.al.(1978). In a study examining the ENERGY EXPENDITURE DURING SIMULATED ROWING an energy contribution was estimated as contributing $70 \%$ to the total energy released. In a pilot study by the present researcher involving oarswomen performing a 7-minute ergometer test, the aerobic metabolism was estimated as contributing $85 \%$ of the energy required. Considering these findings and other literature on the energy demands of various work durations of maximal exercise (Astrand Rodahl, p.316, 1977). Eighty percent of the energy demand of a 2,000 meter national level women's $8+$ race will be contributed by the aerobic energy system.

2) $20 \%$ or $1 / 5$ th of the energy required for a 2,000 meter national level elite women's $8+\left(\begin{array}{ll}6 & 1 / 2 \\ \text { minute }\end{array}\right.$ is contributed by the anaerobic energy system. Rationale:

The rationale for this prediction is again partially based on Hagerman, et.al.(1978) reported findings. Anaerobic energy contribution was estimated 
by calculating $\mathrm{O}_{2}$ debt (post-exercise) as measured during the 30-minute recovery period. Anaerobiosis $\left(\mathrm{O}_{2}\right.$ debt) was calculated as providing $30 \%$ of the energy for the 6-minute ergometer test among oarsmen. The 1985 study by the present researchers (7-minute ergometer test involving oarswomen) estimated anaerobiosis asbeing responsible for $15 \%$ of the energy requirement.Based on these findings and Astrand and Rodahl's literature on emergy demands of maximal work times (1977), $20 \%$ of the energy required for a 2,000 meter national level women's $8+$ race will be contributed by the anaerobic energy system.

3) The national level oarswomen involved will perform the race simulation test at an intensity equivalent to 95-98\% of their $\mathrm{VO}_{2}$ max. (as measured in a PIT on the RE) for the final 5 minutes of the $61 / 2$ minute test.

Rationale:

Previous research findings suggest that oarsmen can work at $95-98 \%$ of their maximal aerobic capacity during the last 5 minutes of a 6-minute RE test (Hagerman, et.al., 1978). The 1985 study of the present researchers reported that collegiate oarswomen worked at $96 \%$ of their $\mathrm{VO}_{2}$ max. in the last $41 / 2$ minutes of the simulation. 


\section{METHODOLOGY:}

\section{SUBJECTS :}

Six candidates for the 1988 Women's Canadian

National Rowing Team, currently training in Vancouver will serve as subjects for this study. Each subject will perform a progressive intensity test and a $61 / 2$ minute race simulation. Both tests will be conducted on the Dr. Gjessing Ergorow ergometer. The subjects age range is from 21 to 27 years.

The subjects will be instructed to warm-up prior to arriving for testing, to ensure an adequate preparation for the exercise. At the lab, body weight and height shall be measured. Following this the ECG (electrocardiogram) leads will be placed in the LV5 arrangement. At this time the attending physician will administer catheter and draw a resting blood sample. Subjects will then be given the opportunity to warm-up on the testing ergometer.

\section{EQUIPMENT:}

Beckman Metabolic Measurement Cart(BMMC)

Hewlett-Packard 3052A data acquisition system

Dr. Gjessing Ergorow rowing ergometer(with variable resistance adjustment)

Hans-Rudolph valve

ECG surface electrodes (Meditrace electodes)

Lactate analyzer (Kontron 640)

Electrocardiogram 
Stroke rate watch ( $\&$ stop watch)

Catheter (Jelco 20 gauge $11 / 4$ inch flexible catheter) Blood collection vials with hemolyzing agent Heparin, 1Cc \& 3cc syringes, saline (0.9\% $\mathrm{NaCl})$, tape, surgical gloves, diluting solution, extension tubing, Alcohol swabs, tournoque

\section{PROGRESSIVE INTENSITY TEST (PIT):}

The purpose of this test is to determine each oarswoman's maximal oxygen capacity during rowing. From these values, the RS intensity can be predicted relative to each individual's $\mathrm{VO}_{2} \max$.

The starting resistance on the flywheel for the PIT will be $1.25 \mathrm{~kg}$ and the stroke rate approximately 30 strokes per minute (Cunningham, et.al., 1975). Subjects are required to maintain a power output that will yield a 600 revolutions per minute score on the ergometer tachometer. The resistance on the flywheel will be progressively increased as outlined in Appendix A.

Subjects are required to maintain the 600 revolutions per minute score until the end of the $6 \mathrm{th}$ minute of the PIT (loading $-2.5 \mathrm{~kg}$ ). At this time, there will be no further increase in the resistance and subjects will be required to increase power output such that the revolutions per minute are increased by 20 revolutions per minute (approx. 3\% increase). Stroke rate will be set by the individual rather than the researchers to allow each oarswoman to work 
at a pace that is most efficient for her. It is expected that the stroke rate will range from 28 to approximately 32 strokes per minute. The subject shall continue the test until a $\mathrm{VO}_{2}$ plateau or decrease, volitional fatigue or continual decrease in power output necessitates termination.

Stroke rates will be monitored with a stroke watch or stop watch while the flywheel revolutions will be monitored and recorded by an electronic digital recorder.

\section{RACE SIMULATION (RS):}

The $61 / 2$ minute race protocol is designed to simulate the duration, intensity and stroke rate of an actual 2,000 meter race in a women's national level eight oared shell. The Dr. Gjessing Ergorow ergometer will be used with a load setting of $2.5 \mathrm{~kg}$ on the flywheel. A tape recorded water race of a female coxswain will lead the oarswomen through the RS by administering verbal commands, stroke rate feedback and relative distances covered.

Prior to the start of the race, the oarswomen will sit relaxed on the ergometer such that a 3-minute pre-test $\mathrm{VO}_{2}$ can be determined. At the conclusion of the 3-minute rest period the simulated race will begin. Therefore, at 2:45 minutes the rower will be instructed to sit-up at $3 / 4$ slide in preparation for the starting commands. On completion of the simulation, subjects shall discontinue rowing and remain seated on the ergometer for a 30-minute 
post exercise ventilatory measurement periods. During recovery, excess post-exercise oxygen consumption will be analyzed and used to predict the anaerobic energy component.

Distance/time relationships for the race simulation will be as follows: 500 meters $-1: 37$ min.

$$
\begin{aligned}
& 1000 \text { meters }-3: 14 \mathrm{~min} . \\
& 1500 \text { meters }-4: 51 \mathrm{~min} . \\
& 2000 \text { meters }-6: 30 \mathrm{~min} .
\end{aligned}
$$

\section{CALCULATIONS:}

(See appendix B)

The excess post-exercise oxygen consumption, as calculated by recovery $\mathrm{VO}_{2}$ values, will consititute the anaerobic component of the simulation (Devries, 1986).

Matched pairs t-tests will be employed to test for significant differences between the maximum mean heart rates, maximum mean $\mathrm{V}_{\mathrm{E}}$, maximum mean excess $\mathrm{CO}_{2}$ and maximum mean $\mathrm{VO}_{2}$ values between the race simulation and the PIT. 
$-17-$

CHAPTER TWO

REVIEW OF

LITERATURE 
ESTIMATING THE RELATIVE CONTRIBUTION OF AEROBIC AND ANAEROBIC METABOLIC CONTRIBUTIONS

In 1985, the oarswomen's racing distance increased from its previous 1;000 meters to 2,000 meters, the equivalent of the oarsmen's races. As a result of this recent alteration, there is no current published literature on the oarswomen's physiological responses to this exercise. In fact, there is a rather limited composite of data available from testing at the 1,000 meter distance (Hagerman, et.al., 1979; Secher, et.al., 1983; Hagerman, et.al., 1984). Data on these athletes is limited to studies involving rowing ergometer tests of 3 to 4 minutes the equivalent of an on water 1,000 meter race in a rowing shell. In contrast, there is a rather extensive pool of data available on oarsmen and their metabolic and cardiorespiratory responses to the 2,000 meter race (Hagerman, et.al., 1978; Mahler, et.al., 1984; Secher, et.al., 1982; Mackenzie \& Rhodes, 1982; Secher, et.al., 1983). Incorporating a literature review of oarswomen's responses at 1,000 meters and oarsmen's responses at 2,000 meters, hypotheses on physiological responses of oarswomen racing 2,000 meters may be formulated.

Hagerman, et.al., (1979) have evaluated elite oarswomen's $(n=40)$ physiological responses to rowing. In a 3-minute race simulation on a stanford side pull rowing ergometer, the aerobic metabolic contribution was found to 
be 55\%. Continuous expiratory gas analysis during a30-minute recovery period permitted an oxygen debt calculation which revealed a $45 \%$ relative contribution of the anaerobic metabolic pathway.

Later, in 1984, Hagerman, et.al., conducted another ergometer test with oarswomen, employing a 4-minute race simulation. Results of these tests indicated a $70 \%$ aerobic metabolic pathway contribution and a $30 \%$ anaerobic contribution to the race. The anaerobic component was further divided into an alactic (10\%) and a lactic (20\%) portion based on an analysis of the $\mathrm{vo}_{2}$ recovery curve (oxygen debt partitioning). These findings are in agreement with the values of Astrand and Rodahl (1977) (table 9-1) which list a 70\%/30\% aerobic/anaerobic energy contribution ratio for a maximal effort of 4 minutes.

In a 1982 study by secher and his colleagues, through oxygen deficit calculations, a $23 \%$ anaerobic contribution to a 4-minute rowing ergometer performed by female rowers was presented. Presumably, if the anaerobic contribution is $23 \%$, the remaining $77 \%$ of energy is provided by the aerobic system. This $23 \%$ anaerobic value is somewhat less than the value of Hagerman, et.al. (1984), and Astrand and Rodahl (1977) (table 9-1), referred to previously.

In a study by Young and Rhodes (1986), 5 collegiate oarswomen were evaluated during a 7-minute, 2,000 meter race simulation on a Gjessing rowing ergometer. The data collected suggested an $83 \%$ aerobic contribution, as 
determined through the continuous evaluation of $\mathrm{VO}_{2}$ throughout the exercise and recovery periods (similar to Hagerman, et.al., 1979). During the recovery, the respiratory gases were continuously collected and evaluated until $\mathrm{VO}_{2}$ values reached pre-exercise levels. With these values, a prediction of oxygen debt was made. Based on the assumption that oxygen debt is a valid measure of anaerobic metabolism, Young and Rhodes predicted a $17 \%$ anaerobic contribution. Referring to Astrand and Rodahl's (1977) maximal effort table, a 10-minute maximal effort exercise is suggested as having a 10-15\% anaerobic and an $85 \%$ to $90 \%$ aerobic contribution. A paper by Gollnick and Hermansen (1973) offers relative percent contribution values contrary to Astrand and Rodahl's. They indicate a 9\% anaerobic and 91\% aerobic contribution to a 10-minute maximal work period. Furthermore, they suggest a 5-minute maximal effort as having a $20 \%$ anaerobic and an $80 \%$ aerobic distribution. The collegiate oarswomen's results of Young and Rhodes closely resemble Gollnick and Hermansen's percentages.

Hagerman (1979) makes reference to a doctoral dissertation by Connors (1974) entitled, 'An Energetic Analysis of Rowing'. In this study, the contribution of the anaerobic energy system was calculated by evaluating the post-exercise blood lactate levels in the oarsmen. Results credited the anaerobic system with $22.2 \%$ of the energy supply for the 6-minute ergometer race. It is 
assumed that the remainder of the energy requirements aresupplied by aerobic metabolism (77.8\%). These results are in discrepancy with the findings of other investigators examining oarsmen's responses to a 6-minute rowing ergometer exercise (Hagerman, et.al., 1979; Secher, et.al., $1982 ; \ldots)$

Szoby and Cherebetiv (1974), investigating the physical work capacity of male rowers, conducted a 6-minute progressive intensity test on a bicycle ergometer. The intensity of the test was designed to exhaust the rowers by the end of the 6th minute of exercise. Calculating an oxygen deficit for each athlete (required $\mathrm{VO}_{2}$ - actual $\mathrm{VO}_{2}=\mathrm{O}_{2}$ deficit), a percentage ratio between exercise $\mathrm{VO}_{2}$ and oxygen deficit was employed to represent the aerobic and anaerobic ratio of the exercise. Mean percentage ratios for the rowers were found to be $68.4 \%$ aerobic and $31.6 \%$ anaerobic. Given that the mode of exercise was not specific to the rowing athlete's sport, it is not surprising that these percentages vary from results on a rowing ergometer.

In contrast to the results of the previous two papers reviewed, Hagerman (1975), in a three year longitudinal study on oarsmen, presents data indicating a $75 \% / 25 \%$ aerobic/anaerobic energy contribution. This study involved a more appropriate means of evaluating oarsmen by employing a rowing ergometer for a 6-minute exercise (constant load) test. Later, in 1978, Hagerman and his associates 
the energy expenditure of oarsmen during simulated rowingusing the 6-minute race simulation on the rowing ergometer. Calculating the aerobic cost of the exercise from the total net $\mathrm{VO}_{2}$ of the work period, it was concluded that $70 \%$ of the relative energy contribution was supplied by aerobic metabolism. oxygen consumption values collected during a 30-minute recovery period were used to calculate an oxygen debt. The value calculated, believed to represent the anaerobic energy component, indicated a $30 \%$ contribution.

Secher,et.al. (1982), calculated the anaerobic energy contribution to the oarsmen's 6-minute rowing ergometer race simulation based on oxygen deficit. Calculations revealed a 14\% anaerobic contribution, a percentage that is in discrepancy with earlier researchers conclusions. The experience of the oarsmen examined or simply the calculation methods may explain the discrepancy here. Many of the earlier papers discussed have implemented oxygen debt (recovery $\mathrm{VO}_{2}$ ) as the means for evaluating anaerobic metabolism while this study employed oxygen deficit.

In view of the following findings:

1) 6-minute $\mathrm{RE}$ race for oarsmen $=70 \% / 30 \%$ aerobic/anaerobic energy ratio (Hagerman, et.al., 1978),

2) 7-minute $\mathrm{RE}$ race for collegiate oarswomen = 85\%/15\% aerobic/anaerobic ratio (Young \& Rhodes, 1986),

3) 4-minute $\mathrm{RE}$ race for elite oarswomen = $70 \% / 30 \%$ aerobic/anaerobic ratio (Hagerman, et.al., 
$1984(a b))$,

the energy contributions of a $6 \quad 1 / 2$-minute rowing ergometer race simulation for national level oarswomen can be hypothesized.

\section{OXYGEN DEBT AS A METHOD OF EVALUATING ANAEROBIC METABOLISM}

Numerous methods are utilized to evaluate anaerobic capacity due to a lack of standardization in accurately estimating anaerobic energy reserves. There are limitations to the measurements of anaerobic capacity regardless of the method used. Factors exist which are unrelated to the replenishment of depleted energy stores (ie. oxygen cost of breathing) may influence the estimation and interpretation of oxygen debt (Welch, et.al., 1970).

In 1970, investigating the relationship between oxygen debt and oxygen deficit, Whipp, et.al., found evidence for the equality of oxygen debt and oxygen deficit in exercise of 4 to 6 minutes duration. The equations used to calculate oxygen deficit and oxygen debt were as follows:

$$
\begin{array}{r}
\text { oxygen deficit }=\mathrm{VO}_{2} \mathrm{ss}-\begin{array}{c}
\mathrm{VO}_{2} \\
\text { actual (dt) }
\end{array} \\
\text { oxygen debt }=\mathrm{VO}_{2} \begin{array}{r}
\text { recovery }-\mathrm{vo}_{2} \\
\text { unloaded } \\
\text { cycling(dt) }
\end{array}
\end{array}
$$

$\{$ ss $=$ steady state; $d t=$ derivative of time $\}$

The intensity of the exercise used was such that a steady state in $\mathrm{VO}_{2}$ was achieved. Therefore, the results may be interpreted to suggest that $\mathrm{O}_{2}$ deficit and $\mathrm{O}_{2}$ debt 
are equivalent in steady state exercise lasting 4 to 6 minutes.

Hagerman, et.al. (1979) instigated a hypothesis that $\mathrm{O}_{2}$ deficit may in fact be a more accurate representation of anaerobic metabolism during rowing, due to the nature of the sport. However, there is no explanation given as to what is meant by 'the nature of rowing'. In the data presented, both oxygen deficit and oxygen debt values for males and females were given. oxygen debt values were found to be $40 \%$ greater than the oxygen deficit values in both groups. The mean net oxygen debt for oarswomen (3-minute $R E$ simulation) was $10.2 \pm 5.5 \mathrm{~L}$ while the mean oxygen deficit value was $6.4 \pm 3.6 \mathrm{~L}$.

In maximal exercise, the oxygen deficit of an individual cannot be estimated with certainty because of the lack of a precise value of the oxygen requirement. It is partly for this reason that investigators have attempted the use of oxygen debt as a measure of anaerobic metabolism during exercise (Brooks \& Fahley, 1984). However, the mechanisms of oxygen debt are quite complex and difficult to use in estimating energy metabolism during exercise. Hagerman, et.al., (1979), studying oarsmen in a 6-minute $\mathrm{RE}$ race simulation, found a mean oxygen debt of 13.4L. Although the simulation appeared to be of a severe steady state type (except during initial minute), fluctuations in the average $\mathrm{VO}_{2}$ values prohibited the assessment and accurate calculation of oxygen deficit. 
Computing the anaerobic component from post-exercise lactate production also appears questionable, due to the inaccuracies which may exist with the energy equivalents associated with lactate production. Despite the controversy surrounding the use of oxygen debt, oxygen deficit and blood lactates, in estimations of the anaerobic energy contribution to specific exercises, the relative contribution of this energy system in 2,000meter rowing appears to rest between 20 and 30 percent (Hagerman, et.al., 1978).

oxygen deficit may possibly be a more accurate measure of the anaerobic metabolism. However, $\mathrm{O}_{2}$ deficit is based on calculations rather than on direct measurements (Secher, 1983a). Furthermore, with the difficulties involved in making an accurate calculation of oxygen deficit, it is rarely employed (Hagerman, 1984). Hermansan and Medbo (1984) have presented data indicating an upper limit to the oxygen deficit based on the duration of the exercise. When maximal exercise duration was increased from 15 seconds to 2 minutes, there was an increase in oxygen deficit from 30 to $83 \mathrm{~mL} \mathrm{O}_{2} / \mathrm{kg}$. However, with a further increase in maximal exercise duration to 4 minutes, no further or a negligible increase in oxygen deficit. These results suggest that oxygen deficit may not be thel most appropriate method for measuring the anaerobic energy contribution to a $61 / 2$ minute race simulation. 
BASELINE $\dot{\mathrm{VO}}_{2}$ AND RECOVERY PERIODS

Values reported for recovery oxygen vary when different recovery baselines are used (Stainsby \& Barclay (1970); Hagerman, et.al., (1978)). To date, three seperate baselines have been used in recovery oxygen examinations. The first baseline is that of the Basal Metabolic Rate (BMR). Complications with this measure are inherent due to its sensitivity. Achieving a BMR requires specific resting conditions which are very difficult to achieve under laboratory conditions prior to an exercise performance. Furthermore, re-establishing the BMR post-exercise requires a lot of time after intense and long duration exercise. Finally, the values recorded tend to be quite large. Due to the tediousness of achieving the BMR, it is rarely used as a baseline $\mathrm{VO}_{2}$.

The second and most commonly used baseline is that of resting metabolic rate (RMR). However, there is question as to the components of recovery that are actually measured when RMR is the baseline. When measuring the RMR, the conditions that created this value are presumed to continue unchanged throughout the exercise and recovery periods. This is an unlikely presumption as anticipation of the coming exercise alone may artifically alter the resting metabolic rate before the actual exercise. Furthermore, it is quite unlikely that this same anticipatory response will continue into the exercise and recovery periods (Stainsby \& 
Barclay, 1970).

The third baseline $\mathrm{VO}_{2}$ is that of a working $\mathrm{VO}_{2}$ baseline. This method is presumed to yield the smallest recovery $\mathrm{VO}_{2}$. The question is whether some of the recovery components from the exercise test are precluded if activity is continued (ie. ion \& metabolic replacement). In conclusion, it is quite evident that the baseline level of oxygen uptake used for calculation of recovery oxygen has a profound effect on the size of the recovery oxygen. Therefore, the choice of baseline must be considered carefully (Stainsby \& Barclay, 1970; Hermansan, et.a1.,1984).

In the many studies reviewed by this researcher, the use of resting and mild exercise $\mathrm{VO}_{2}$ baselines have dominated. Whipp, et.al., (1970), examining oxygen debt and oxygen deficit relationships employed an 8-minute unloaded cycling period (0 $\mathrm{kg}-\mathrm{m} / \mathrm{min})$ at $60 \mathrm{rpm}$ prior to an abrupt increase in work rate to $685 \mathrm{~kg}-\mathrm{m} / \mathrm{min}$. Following the exercise phase (of between 1 \& 6 minutes) the subject was required to cycle at $60 \mathrm{rpm}$ at a $0 \mathrm{~kg} \cdot \mathrm{m} / \mathrm{min}$. loading for a 35 minute recovery period. Results indicated that at the conclusion of 15 minutes of unloaded cycling, recovery to pre-exercise $\mathrm{VO}_{2}$ (as measured during unloaded cycling) was attained, indicating a rapid oxygen debt repayment. Cowan and solandt, in 1937, also used mild exercise on a bicycle ergometer to achieve a recovery baseline $\mathrm{VO}_{2}$ value. The strenuous exercise involved running on the 
for 30 seconds as fast as possible. Following thisexercise phase, subjects remounted the cycle-ergometer and cycled at the same pre-exercise intensity until baseline $\mathrm{VO}_{2}$ 's were achieved. Recovery was completed 20 to 45 minutes post-exercise. Recently, a rowing study in 1978 (Hagerman, et.al.) also used a mild exercise $\mathrm{VO}_{2}$ as a baseline for oxygen debt calculations. Using a lkg loading on a Gjessing rowing ergometer, oarsmen performed a 10-minute exercise bout at a stroke rate of $26 \mathrm{spm}$. Following the 6-minute ergometer test, a 30-minute recovery period of rowing at $26 \mathrm{spm}$ with a $1 \mathrm{~kg}$ loading was performed. In their analysis, the investigators of this study stated that light exercise during recovery may have enhanced lactate resynthesis.

Examining the aerobic recovery after anaerobiosis in rest and work, Asmussen (1946) used a resting $\mathrm{VO}_{2}$ baseline. The subject involved was seated in a reclining chair fitted to a cycle ergometer. with such a set-up no energy would be required by the subject to get on and off the bicycle, reducing the probability of falsely inflating the recovery $\mathrm{Vo}_{2}$. Later, in 1964, Margaria, et.al., also used a resting $\mathrm{VO}_{2}$ as the baseline. Measurements were made while subjects stood on the testing treadmill prior to a 5-30 second work bout. On completion of the work bout, subjects again stood on the treadmill as gas analysis continued. Rowing specific studies by Hagerman, et.al. (1979) and Young and 
Rhodes (1986) employed similar resting $\mathrm{VO}_{2}$ collections to evaluate oxygen debt. oxygen consumption was measured during resting state, pre-exercise, while subjects sat on the rowing ergometer (Young \& Rhodes, 1985). Following completion of the all-out ergometer simulation subjects remained seated on the ergometer as gas collection continued for a period of 15 to 30 minutes.

Regardless of the baseline $\mathrm{VO}_{2}$ implemented, most of the literature examining oxygen debt employs a 30-minute recovery period with which to evaluate the subject. Among these studies are: Hagerman, et.al., 1978; Hagerman, 1984; Hermansen \& Vaage, 1977; Evans \& Cureton, 1983; Welch, et.al., 1970. Although some investigators have found recovery $\mathrm{VO}_{2}$ reaches baseline levels prior to the end of a 30-minute recovery period (Cowan \&Solandt, 1937; Hagerman, et.al., 1978), this duration appears to be relatively standard practice.

\section{PULMONARY VENTILATION}

During constant-rate exercise there are three response phases of the ventilation rate. The initial or first phase is an immediate increase with the initiation of exercise. The second phase is a slower increase to a steady-state level, while the third phase is a steady state level. In heavy exercise, the initial response will be a smaller fraction of the phase III response. Sometimes, phase II 
lasts longer, never reaching a steady state level (ie. 3 to4 minute race simulation). It is well documented that when metabolic acidosis occurs, there is an increase in ventilation, predominantly the result of an elevation in respiration rate, out of proportion with the elevation of $\mathrm{VO}_{2}$. The ventilatory response to exercise has been found to be an excellent index of the ability of subjects physiological gas transport mechanisms to meet cellular oxygen requirements.

Cunningham, et.al. (1975) suggested that a reduced $\mathrm{V}_{\mathrm{E}} / \mathrm{VO}_{2}$ (ventilatory ratio) during simulated rowing was primarily due to the cramped body position of the oarsman at the catch phase of the rowing stroke. These investigators felt that this body posture may provide significant impairment of excursion of the diaphragm. It is further suggested that the cyclical breathing of the rower further decreases the pulmonary ventilatory volume (ie. two breaths/stroke at maximal exertion).

In contrast, Hagerman and Lee (1971) found $V_{E}$ (BTPS) for oarsmen during a race simulation to be relatively high. In fact, on comparing $V_{E}$ (BTPS) values for the same subjects when tested on a $20 \%$ grade maximal treadmill run, the $v_{E}$ rowing was $161 \mathrm{~L}$ while the $\mathrm{V}_{\mathrm{E}}$ running was $40 \mathrm{~L}$ less at 121L. Furthermore, investigators (Hagerman, et.al. (1978), Bouchant, et.al. (1983), and Mahler, et.al. (1987) ) examining oarsmen and oarswomen found no evidence to support the hypothesis of pulmonary ventilatory 
impairment during maximal work on a rowing ergometer aspreviously suggested by Cunningham, et.al. (1975).

Investigating the physiological profiles of elite oarsmen and oarswomen in 1979, Hagerman, et.al., reported values of $190 \mathrm{~L} / \mathrm{min}( \pm 11.3)$ [BTPS] and $165 \mathrm{~L} / \mathrm{min}$ $( \pm 15.6)$ [BTPS] respectively, during race simulation. These researchers suggest that it is not unusual for oarswomen to maintain an average $v_{E}$ of over $170 \mathrm{~L} / \mathrm{min}$ [BTPS] for a 3 to 4 minute maximal rowing effort. In contrast, young and Rhodes (1986), examining collegiate oarswomen's physiological responses during a 7-minute race simulation, found a substantially lower mean maximal $V_{E}$ [BTPS], $138.62 \mathrm{~L} / \mathrm{min}( \pm 13.22)$. Although both race simulations were of maximal intensity, the 7-minute simulation would allow the attainment of a steady state which a 3 to 4 minute test would not. Consequently, the ventilatory response of the 7-minute race is lower since the levels attained are maintained for a longer duration. It is also possible that variance in subject caliber, influences the maximal $v_{E}$ attained. The less experienced subjects ventilatory capabilities could be restricted by lack of volume of rowing specific cardiorespiratory training (Young \& Rhodes, (1986), Mahler, et.al. (1987)). It is also possible that the physical size difference in the subject pools of these studies may partially account for some of the discrepancy. Bouchant, et.al. (1983), investigated cardiorespiratory responses to bicycle and rowing 
ergometer exercise in oarsmen. The data collected provided no evidence to indicate an impairment of pulmonary ventilation during maximal R.E. effort. Comparing the relationship between pulmonary ventilation (VE) and oxygen uptake for the bicycle ergometer test and the rowing ergometer test, $\mathrm{v}_{E}$ was slightly higher on the rowing ergometer $\left[\begin{array}{ll}150 & ( \pm 10) \mathrm{L} / \mathrm{min} \text { R.E. vs. } 149( \pm 12) 1 / \mathrm{min} \text { B.E.] }\end{array}\right.$ Even with the control group of this study, only small non-significant differences were found between the B.E. and R.E. maximal pulmonary ventilation.

"Energy expenditure during simulated rowing" by Hagerman, et.al. (1978), involved a race simulation on a rowing ergometer lasting 6-minutes. Metabolic data was collected throughout the exercise period. A significant response was noted in the pulmonary ventilation with the mean maximal ventilatory volume at $190 \mathrm{~L} / \mathrm{min}$ [BTPS]. No evidence was found to indicate any impairment of pulmonary ventilation during the rowing sequence, despite the occurence of inspiration at the catch position (cramped body position). Furthermore, the ventilatory equivalents measured in this test, although lower than the values reported by Cunningham, et.al.'s (1975), suggest an excellent cardiorespiratory efficiency.

BLOOD LACTATE RESPONSES TO ROWING RACES

Research findings indicate an association between high 
muscle and blood lactate levels with both fatigue and a reduction of exhaustive exercise performance time (Koutedakis \& Sharp, 1985). Lactate ions diffuse freely between tissues and blood as evidenced by a prompt appearance and a rapid decrease in the concentration of lactate as blood passes through an inactive area of the body. It is assumed that the blood lactate concentration is proportional to the amount of lactate in the body (ie.muscles) (Margaria, et.al., 1933). (An exception to this would be in the case of such a rapid change in the lactic acid production that equilibrium between [lactic acid] in tissues and blood has not been achieved.) Research findings of Graham, et.al. (1976) demonstrate that, depending on the time of blood sampling, blood lactate may or may not be indicative of muscle lactate. Despite the inherent difficulties in determining the distribution volume for lactate, blood and/or muscle lactate have previously been used in the assessment of anaerobic metabolism.

Gollnick and Hermansen (1973), in a review of anaerobic metabolism, presented findings indicative of an approximately equal concentration of muscle lactate after maximal exercise even when the durations of exercise were varied. For example, the concentration of lactate in the muscles after 2 to 3 minutes of maximal exercise $(1,000$ meters) is approximately equal to the concentration found after 7 minutes of exercise $(2,000$ meters). Consequently, 
it is quite possible that the peak blood lactate concentration measured after a 3 or 4 minute rowing ergometer race simulation (women's 1,000 meters) will be similar to the peak values in a $61 / 2$ minute race simulation. In fact, blood lactates measured after a 7 minute R.E. race simulation with collegiate oarswomen (Young \& Rhodes, 1986) do not indicate substantial variation from the blood lactate values reported by Hagerman, et.al. (1979) for a women's 3 minute R.E. race simulation.

In 1978, Hagerman, et.al., measured blood lactate levels in oarsmen at rest, 5 and 30 minutes following a 6 minute race simulation. In comparing these results with the results of a randomly terminated 6 minute ergometer test (investigators stopped subjects at $1,2, \ldots \& 5 \mathrm{~min}$. into the 6 minute simulation), it was concluded that $90 \%$ of the lactates were formed during the first minute of the 6 minute test. Furthermore, the lactate levels peaked at 2 minutes into the test. Lactates were found to remain elevated and relatively stable until the conclusion of the work period. These results suggest that little or no lactate resynthesis occurs during the 6 minute exercise test. It is hypothesized (Hagerman, et.al., 1978) that glycolysis diminishes after a steady state is achieved and that the lactic acid accumulated prior to this state remains constant unless exercise intensity is increased. Post-simulation blood lactate values reported in this 1978 
study were $168 \mathrm{mg} / 100 \mathrm{~mL}$ blood, attesting to the severity of the exercise and the contribution from the anaerobic system (Astrand \& Rodahl, 1977). The formation of lactate in the body may be related to the intensity of exercise as well as to the metabolic profile of the contracting muscles. It has been suggested that the appearance of lactate in muscle and blood is related to an insufficient supply of molecular oxygen in the contracting muscles. However, even in the presence of adequate molecular oxygen, the specific recruitment of the type II muscle fibers may lead to an excess lactate formation (Sjodin, et.al.,1979). In 1982, Mackenzie and Rhodes examined the lactate profiles of elite oarsmen $(n=8)$ during a 5:45 minute R.E. test. The results of their study indicated a significant and rapid increase in blood lactate levels 1 minute into the ergometer test. The serum lactate levels continued to rise throughout the exercise period peaking at 14.7 mmol/L. At two minutes into the recovery period, the recovery value measured $13.85 \mathrm{mmol} / \mathrm{L}$. These results were not expected as serum lactate levels generally contiunue to increase during the initial few minutes of recovery. The investigators attributed these results to the possibility of the highly trained athletes involved to oxidize lactic acid within the skeletal muscle.

Employing a 6 minute R.E. test to determine oarsmens maximal aerobic capacity, Secher, et.al. (1982) also collected blood samples at 3 and 5 minutes post-exercise. 
The mean blood lactate reported was $12.5 \mathrm{mmol} / \mathrm{L}$. Later, in 1985, Koutedakis and Sharp examined oarsmen's blood lactates following a 2,000 meter on-water race. Finger tip blood samples drawn 1 minute post-exercise revealed blood lactates ranging from $12.22 \pm 1.09 \mathrm{mmol} / 1$ to $12.61 \pm 0.94$ mol/L. These on-water values closely resemble the ergometer test lactates of secher, et.al. (1982) - However, Koutedakis and Sharp's samples were made earlier in the post-exercise period and therefore, the levels reported may be lower than a 3-minute post-exercise sample might reveal. Examining the physiological profiles of elite rowers, Hagerman, et.al. (1979) reported values of $149 \mathrm{mg} / 100 \mathrm{~mL}$ ( $14.2)$ and $168 \mathrm{mg} / 100 \mathrm{~mL}( \pm 15.6)$ for women and men respectively. The magnitude of these values is indicative of the large demand placed on the anaerobic energy system during a rowing race $(1,000$ or 2,000 meters). Later, in 1984, when Hagerman, et.al., studied the oarswoman's responses to a 4-minute (1000 meter race simulation) ergometer test, a 3 minute post-exercise lactate of 130.6 $\mathrm{mg} / 100 \mathrm{~mL}$ was found. Again these results also indicate a heavy taxing of the anaerobic energy system. A portion of the discrepancy in the [lactic acid] values of the two studies may be due to a caliber variation in the subject pools examined. 
PROGRESSIVE INTENSITY EXERCISE

When testing the $\mathrm{VO}_{2}$ max. of highly trained athletes, the movement patterns of the test should be as precisely matched to the subjects mode of training and racing as possible (Thaden, et.al. (1982) (chapter 4) \& Stromme, et.al. (1977)). A potential problem with the rowing ergometer that has been evident in the past, is that the oarswomen may begin their test at more that $60 \%$ of their $\mathrm{VO}_{2} \max . . \quad$ However, because of the good feasibility of the rowing ergometer and the importance of sports specific exercise (Steinocher, et.al. (1983)), this testing apparatus seems to be the most appropriate choice for investigating physiological responses of oarspersons. In support of this, Fiegenbaum, et.al. (1983) examined cyclists and oarsmen in progressive intensity tests (PIT) on a bicycle ergometer and a Gjessing rowing ergometer. Their results indicated a dependence of exercise efficiency measured in the lab on the mode of strain and sports-specific dexterities of the sportsmen's training. Further, Hagerman and Staron (1983), evaluating seasonal variations among physiological variables in elite oarsmen, found that there are most definitely specific aerobic training effects from on-water rowing. Even though the oarsmen trained rigorously year long in an aerobic conditioning program of running, cross-country skiing and rowing ergometer work, it was the rowing specific in-season 
training that yielded a comparatively higher $\mathrm{VO}_{2} \max$.

Droghetti, in 1986, used the Gjessing R.E. to evaluate the $\mathrm{VO}_{2}$ max. of 20 men and 1 woman, all members of the Italian National Rowing Team . The loading on the flywheel and the stroke rate were kept constant (women $2.5 \mathrm{~kg} /$ men $3.0 \mathrm{~kg})$. Work output was increased by increasing the number of flywheel revolutions each minute. For the oarswoman tested, increases varied from 8 to 12 watts each minute (approx. 7 revs/ min.). With such small increments in power output, it may have been difficult for the athletes to monitor their power application, even with feedback.

Rationale for the use of a rowing ergometer, versus a treadmill or cycle ergometer, in evaluating rowers has been exemplified in past research with these athletes. It has been suggested that maximal aerobic power of the athlete may be the limiting factor in rowing performance. These conclusions are based on the data collected and extrapolations made by secher, 1971 (as referenced by. Astrand \& Rodahl, 1977) and Secher, 1982a. Secher found a positive correlation between the average $\mathrm{VO}_{2}$ of men's crews and their placings in international competition. Examining five oarsmen of the Harvard crew, Carey, et.al. (1974) found a non-significant difference in the treadmill $\mathrm{VO}_{2} \max$. and the $\mathrm{RE} \mathrm{VO}_{2} \max$. tests $(\mathrm{p}<.025)$. Based on their findings, they concluded that either testing apparatus could be used to assess the oarsmen's working 
capacity. Rosiello, et.al. (1987) further concluded that $\mathrm{VO}_{2}$ max. on the cycle ergometer and the concept II R.E. were identical. However, in conducting a PIT with oarsmen of varying experience levels, the calibre of the rowers being examined should not be overlooked. If the athlete is inexperienced ( $<3$ years) a non-significant difference between testing apparatus is more likely the result of a lack of rowing specific biomechanical and physiological adaptations. Mahler, et.al. (1987), examining oarswomen, concluded that sport specific (rowing) testing was limiting. Using a bicycle ergometer and a concept II variable resistance rowing ergometer, the maximal oxygen consumptions of trained and untrained females were evaluated. Results were indicative of a lower $\mathrm{VO}_{2} \max$. on the R.E. as a significant difference appeared between the bicycle ergometer and $\mathrm{R} . \mathrm{E}$. $\mathrm{VO}_{2} \max$. in both trained and untrained subjects. Once again, the calibre or experience of the collegiate oarswomen in the investigation must be considered. If, as in Carey, et.al. (1974), the oarswomen have not been rowing for at least a few years, a lack of rowing specific adaptations to the physiological workings of the athlete may explain the results. Furthermore, the protocol and testing apparatus could be questioned as to their reliability and ease of testing. In 1977, stromme, et.al., tested eight elite male rowers, both on the water and on the treadmill (20 degrees uphill grade). Testing involved maximal efforts of 
approximately 4 minutes. Results were indicative of a significant difference (4.2\%) between rowing and running, rowing yielding the higher $\mathrm{VO}_{2} \max$.. Note that the calibre of athlete involved was national (elite), presumably with many years of rowing specific training. In conclusion, stromme, et.al. (1977) emphasized that the type of $\mathrm{VO}_{2}$ max. test is an important factor to consider in the evaluation of specifically trained athlete's maximal aerobic power.

Measuring a national level oarswoman's maximal aerobic power on a R.E. appears to be the best method for such an evaluation. If the athlete is striving for excellence in rowing, training adaptations should be such that a direct effect on physiological variables is indicated through sport specific testing. Furthermore, if a comparison is to be made between an oarswoman's $\mathrm{VO}_{2} \max$. and her performance $\mathrm{VO}_{2}$ during a 2,000 meter race it is logical to evaluate her maximal capacity $\left(\mathrm{VO}_{2} \max .\right)$ on the same apparatus as her racing performance is evaluated (ie. rowing ergometer). 
$-41-$

CHAPTER THREE

METHODOLOGY 


\section{METHODOLOGY}

\section{$\underline{\text { SUBJECTS }}$}

\section{Six candidates for the 1988 Canadian National}

Women's Rowing Team, currently training in British columbia will serve as subjects for this research study (some subjects have been members of the team in previous years). Each subject was required to perform two exercise tests on the Dr. Gjessing Ergorow rowing ergometer. The first test will be a 6 1/2 minute race simulation (SIM) and the second test, a progressive intensity test (PIT). Physical characteristics of the subjects are listed in Table I.

\section{PROCEDURES}

Following arrival at the laboratory, subjects height and weight was recorded and a consent form signed. Three electrocardiograph (ECG) leads were then placed in an LV5 arrangement on the subjects chest. At this time, a Jelco IV 20 gauge $11 / 4$ inch flexible catheter was inserted, under sterile conditions, in the cephalic vein of the right arm by attending physician. Once the catheter was secured, a pre-warm-up sample was drawn and placed in a vial containing a hemolyzing agent.

At this time, subjects were required to perform the pre-set ergometer warm-up (PIT=5min. at $2 \mathrm{~kg}$; $\mathrm{RS}=10 \mathrm{~min}$. at $2 \mathrm{~kg}$ ). On completion of the warm-up, a 3-minute post-exercise blood lactate was drawn. Approximately, 5 
minutes post warm-up the corresponding exercise test began. Blood samples were later analyzed using an automated enzymatic technique (Kontron 640). Prior to analysis of each subjects blood samples, the lactate analyzer was calibrated with $1.0 \mathrm{mmol} / \mathrm{L}$ and $0.5 \mathrm{mmol} / \mathrm{L}$ standard solutions. A 18 to 1 dilution factor was used for the 20 micro litre blood samples.

Metabolic parameters were measured with a Bechman Metabolic Measurement cart (BMMC), interfaced with a Hewlett-Packard 3052A data acquisition system. The data acquisition system allowed for rapid on-line feedback every 15 seconds on the respiratory gas exchange variables.

\section{RACE SIMULATION}

The $61 / 2$ minute race simulation (RS) was designed to simulate the duration, intensity and stroke rating of an actual 2,000 meter race in a national level women's eight. The Dr. Gjessing Ergorow rowing ergometer was used with a load setting of $2.5 \mathrm{~kg}$ (standard National Team testing load; Droghetti, 1986) on the flywheel. A taped recording of an actual 2,000 meter on-water race provided the oarswomen with familiar race commands and sound effects (distance, crew positions, power pieces, etc.). The subject listened to the recording on the headphones of a portable tape cassette player. 
The coxswain began verbal assistance 45 seconds prior to the start of the race, in preparation for the race. During a 3-minute relaxed period, prior to the start of the race, metabolic monitoring proceeded. The race official (on the tape) gave the starting commands while the coxswain provided the race commands. No verbal assistance was given by the investigators during the simulation, in an effort to standardize all simulations.

At the completion of the race simulation, subjects discontinued rowing and remained seated on the ergometer for a 30-minute post-exercise blood and metabolic measurement period. This recovery period allowed for the examination of anaerobic metabolism could be made.

Blood samples were drawn every minute during the $61 / 2$ minute simulation enabling blood lactate profiles to be determined. During the recovery phase, blood samples were drawn each minute up to the 15 minute point (1/2 of the volume of lactate is expected to be removed in 15 minutes, Margaria, et.al. (1933)). The speed of removal of lactate in recovery is proportional to the concentration of lactic acid and is an exponential function of time. Blood lactates were later analyzed in duplicate.

\section{PROGRESSIVE INTENSITY TEST}

The starting resistance on the flywheel for the PIT was set at $1.25 \mathrm{~kg}$, and the stroke rating at approximately 30 spm (Cunningham, et.al., 1975). Subjects were required 
to maintain a power output that yielded a 600 revolution per minute score on the tachometer of the ergometer. The resistance applied to the flywheel was then progressively increased (as outlined in appendix A). Power output was to be maintained at 600 revolutions per minute (300revs/30seconds) as resistance increased, until the completion of the 6 th minute. At this time, the resistance remained at the $2.5 \mathrm{~kg}$ setting and the subject increased her power output such that the number of revolutions completed per minute increased by approximately 20 . The stroke rates employed were set by the individual herself to allow the athlete to row at the pace most efficient for her. It was assumed that these athletes were well attuned to their most efficient stroke rate. Stroke rates were expected to range between 28 and 32 strokes per minute (the higher rates occuring later in the test). (These predictions were based on pilot study results by the current investigator.) The PIT was discontinued when any of the following criteria were met: vo2 plateau or decreased, volitional fatigue, power output drop (consistantly over 2 to 3 minutes.

Stroke rates were monitored with a stroke watch so that feedback could be given to the oarswomen. Flywheel tachometer readings were monitored and recorded by an electronic digital recorder at 15 second intervals. Athletes could see the visual display of revolutions (if they desired to), to aid their power output monitoring. 
Verbal assistance was also given to the athlete (revs. \& stroke rate) to further aid her monitoring. It has been acknowledged that there are difficulties with respect to power output for this study which are inherent in the design of the rowing ergometer and the mechanics of the rowing stroke.

At the completion of the PIT, subjects removed mouthpiece and nose clips. Venous blood samples were drawn each minute during the first five minutes of the recovery, after which the catheter was removed.

To ensure an adequate and consistent pre-test warm-up, a 5-minute warm-up period on the ergometer was required by each subject. The loading on the ergometer was $2.0 \mathrm{~kg}$. The digital counter was connected to allow subjects to familiarize themselves with its operation. Venous blood samples were drawn pre-warm-up and 5-minutes post-warm-up via the indwelling catheter. During the test and recovery, blood was drawn and heart rates recorded in the last 10 seconds of each minute.

\section{CALIBRATIONS}

Prior to the start of each test, the Bechman Metabolic Measurement Cart was calibrated. Room temperature and barometric pressures were recorded and entered into the data acquisition system. Bechman mixing chamber temperature was checked prior to each subjects test. Gas samples of $15.99 \% \mathrm{O}_{2}$ and $3.96 \% \mathrm{CO}_{2}$ were processed 
through the machine to calibrate the gas analyzers. Volume transducer gain adjustment was clibrated with a $1.1 \mathrm{~L}$ syringe. Ten full strokes of the syringe were used to calibrate the volume transducer.

\section{CALCULATIONS}

\{see appendix $B\}$

POST-EXERCISE VO2

-calculated as the difference between total vo2 of the recovery period and the oxygen uptake attributed to baseline conditions during that period.

-based on calculation procedures of Devries, 1986. RESTING $\mathrm{VO}_{2}$

-baseline $\mathrm{VO}_{2}$ value will be obtained by averaging the $\mathrm{VO}_{2}$ measures recorded during the pre-exercise period ( 3 minutes) (provided the $V_{E}$ values are consistent\}. TOTAL OXYGEN UPTAKE

-calculated as the total $\mathrm{vo}_{2}$ of work and recovery periods during the $\mathrm{RS}$ and recovery period minus $\mathrm{VO}_{2}$ for equivalent period of rest. AEROBIC EXERCISE COMPONENT

-calculated as the difference between the total $\mathrm{VO}_{2}$ of the exercise and recovery periods and that of the exercise recovery period alone.

-this value will also be expressed as a percentage relative to total $\mathrm{Vo}_{2}$. 


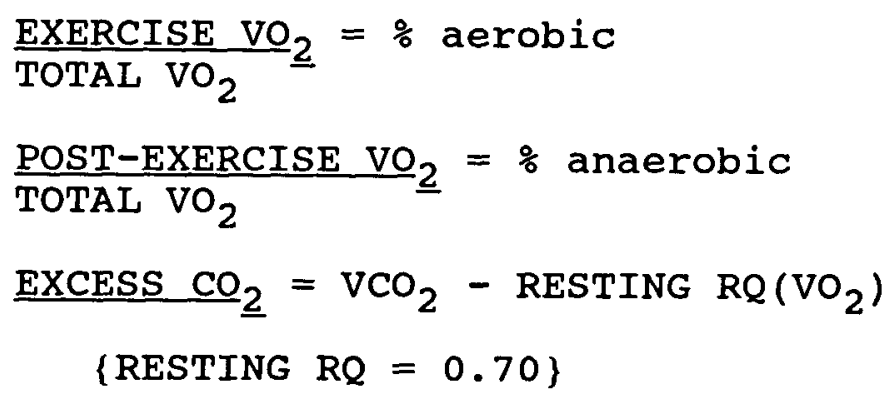

\section{STATISTICAL TREATMENT}

Matched pairs $t$-tests were used to determine the existence of significant differences between the RS and PIT maximal values. 
$-49-$

CHAPTER FOUR

RESULTS \&

DISCUSSION 


\section{RESULTS}

In table I, the physical characteristics of the six national level oarswomen are presented. The age range of the group was 21 to 27 years, the average age being 24.5 years $( \pm 2.4)$. Body weights varied from a low of $65.2 \mathrm{~kg}$ to a high of $90.5 \mathrm{~kg}$. The group's average weight was $75.14 \mathrm{~kg}$ ( \pm 9.5$)$, probably a slightly inflated value due to the weight of the largest subject. Heights of the oarswomen averaged at $178.72 \mathrm{~cm}( \pm 9.02)$. Both the height and weight standard deviation values are quite large, given the individual variability and sample size $(n=6)$. The heaviest athlete was also the tallest of the group, while the lighest and shortest individuals were two different oarswomen.

\section{PROGRESSIVE INTENSITY TEST VS RACE SIMULATION}

The results of the progressive intensity test (PIT) and the race simulation (RS) are presented in table II. $\mathrm{VO}_{2}$ values are expressed in absolute terms (L/min) to best represent the oarswomen's aerobic capacity in a weight supported sport such as rowing. The PIT, designed to stimulate maximal cardiorespiratory responses from the oarswomen, elicited a mean vo2max. of $3.89 \mathrm{~L} / \mathrm{min}( \pm 0.27)$. Maximal oxygen consumption values for each athlete's RS were also recorded (average of the 4 highest $\mathrm{VO}_{2}$ values in $\mathrm{RS})$, yeilding an average maximal value of $3.85 \mathrm{~L} / \mathrm{min}$ $( \pm 0.24)$. Two subjects elicited higher $\mathrm{VO}_{2} \max$. values 
TABLE I PHYSICAL CHARACTERISTICS

\begin{tabular}{clll} 
SUBJECT & AGE (years) & WEIGHT $(\mathrm{kg})$ & HEIGHT $(\mathrm{Cm})$ \\
\hline A & 21 & 78.5 & 179.5 \\
B & 24 & 65.5 & 172.5 \\
C & 23 & 73.3 & 168.4 \\
D & 27 & 77.0 & 186.9 \\
E & 25 & 65.1 & 173.4 \\
F & 27 & 90.5 & 191.6 \\
X & 24.5 & 75.1 & 178.7 \\
S & \pm 2.4 & \pm 9.5 & \pm 9.02
\end{tabular}


TABLE II

RACE \& P.I.T. PHYSIOLOGICAL PARAMETERS

SUBJECT

$\begin{array}{lllllll}\text { MAX. } & \text { AVERAGE MAX. } & \text { MAX. } & \text { MAX. } & \text { AVERAGE } & \text { MAX. } \\ \text { VO2 } & \text { VO2 } & \text { VE } & \text { HR } & \text { EXCESS } & \text { REVS. } & \text { RER } \\ (1 / \mathrm{min}) & (1 / \mathrm{min}) & (1 / \mathrm{min}) & (\mathrm{bpm}) & \mathrm{CO2} & \text { PER MIN. } \\ & & & & (\mathrm{m} 1 / \mathrm{kg} / \mathrm{min})\end{array}$

$\begin{array}{lllllllll}\text { A } & \text { RS } & 4.02 & 3.83 & 122.4 & 189 & 18.5 & 555 & 1.07 \\ & \text { PIT } & 3.89 & & 125.9 & 185 & 23.9 & & 1.18 \\ \text { B } & \text { RS } & 3.48 & 3.32 & 106.1 & 205 & 21.39 & 528 & 1.09 \\ & \text { PIT } & 3.56 & & 120.2 & 204 & 25.24 & & 1.18 \\ \text { C } & \text { RS } & 3.92 & 3.74 & 124.9 & 190 & 22.69 & 572 & 1.13 \\ & \text { PIT } & 3.88 & & 132.2 & 194 & 27.29 & & 1.23 \\ & \text { RS } & 3.60 & 3.53 & 111.68 & 195 & 15.84 & 506 & 1.04 \\ \text { D } & \text { PIT } & 3.64 & & 116.6 & 200 & 19.92 & & 1.16 \\ & \text { RS } & 3.90 & 3.85 & 136.2 & 188 & 21.17 & 594 & 1.06 \\ & \begin{array}{l}\text { RIT } \\ \text { PIT }\end{array} & 4.06 & & 140.7 & 188 & 22.66 & & 1.08 \\ \text { F } & \text { RS } & 4.07 & 3.98 & 133.4 & 190 & 19.24 & 617 & 1.11 \\ & \text { PIT } & 4.30 & & 144.4 & 185 & 24.16 & & 1.19\end{array}$

$\begin{array}{llllllllr}\bar{X} & \text { RS } & 3.85 & 3.71 & 122.4 & 192.8 & 19.81 & 562 & 1.09 \\ & \text { PIT } & 3.89 & & 129.99 & 192.7 & 23.86 & & 1.17 \\ & & & & & & & \\ \text { SS } & \text { RS } & \pm 0.24 & \pm 0.24 & \pm 11.83 & \pm 6.43 & \pm 2.47 & & \pm 0.03 \\ & \text { PIT } & \pm 0.27 & & \pm 11.11 & \pm 8.04 & \pm 2.48 & & \pm 0.05\end{array}$

[NB: AVER. $\mathrm{VO}_{2}=$ average $\mathrm{VO}_{2}$ from $3 \mathrm{rd}$ to $61 / 2 \mathrm{~min}$. of RS] $\mathrm{RS}=$ race simulation $\quad \mathrm{PIT}^{2}=$ progressive intensity test 
during the RS than in the PIT. However, statistical analysis of the $\mathrm{VO}_{2} \max$. values from the PIT and $\mathrm{RS}$ (matched pairs t-test) indicates a non-significant difference between the two tests $(p>01)$. Maximal heart rates (HR) reported in the PIT and RS averaged $193 \mathrm{bpm}$ in both tests with no measurable significant difference $(p>01)$. The mean maximal ventilatory values of the PIT, $130 \mathrm{~L} / \mathrm{min}( \pm 11.1)$ and of the RS, $122.4 \mathrm{~L} / \mathrm{min}( \pm 11.8)$ are significantly different $(p<.01)$. Furthermore, a significant difference in the max. excess $\mathrm{CO}_{2}$ of the PIT and RS is also evident. Mean max. excess $\mathrm{CO}_{2}$ of the PIT was $23.86 \mathrm{~mL} / \mathrm{kg} / \mathrm{min}( \pm 2.48)$ and in RS was $19.81 \mathrm{~mL} / \mathrm{kg} / \mathrm{min}$ $( \pm 2.47)$. All six of the oarswomen exhibit higher $v_{E} \max$. and max. excess $\mathrm{CO}_{2}$ values in the PIT than in the RS. Maximum RER's recorded for the RS, after severe steady state level attained, averaged at $1.09( \pm 0.03)$ amongst the six subjects. RER data from the first minute is not included in mean max. RER calculations, as values are falsely elevated through a probable hyperventilation versus a true metabolic responses.

\section{RACE SIMULATION}

Individual and mean values for resting, exercise, recovery and total (exercise +recovery) oxygen consumption $\left(\mathrm{VO}_{2}\right)$ are listed in table III. Equations and sample calculations of these values are reported in appendices $B$ and $c$. The average resting $\mathrm{VO}_{2}$ for the six oarswomen 


\begin{tabular}{|c|c|c|c|c|}
\hline SUBJECT & $\begin{array}{l}\text { RESTING } \\
\text { VO2 (L) }\end{array}$ & $\begin{array}{c}\text { EXERCISE } \\
\text { VO2 (L) }\end{array}$ & $\begin{array}{c}\text { RECOVERY } \\
\text { VO2 (L) }\end{array}$ & $\begin{array}{l}\text { TOTAL } \\
\text { VO2 (L) }\end{array}$ \\
\hline $\mathrm{A}$ & 0.42 & $\begin{array}{l}20.26 \\
(80.6 \%)\end{array}$ & $\begin{array}{l}4.88 \\
(19.4 \%)\end{array}$ & $\begin{array}{l}25.14 \\
(100 \%)\end{array}$ \\
\hline B & 0.35 & $\begin{array}{l}17.74 \\
(80.2 \%)\end{array}$ & $\begin{array}{l}4.38 \\
(19.8 \%)\end{array}$ & $\begin{array}{l}22.12 \\
(100 \%)\end{array}$ \\
\hline C & 0.47 & $\begin{array}{l}19.69 \\
(78 \%)\end{array}$ & $\begin{array}{l}5.57 \\
(22 \%)\end{array}$ & $\begin{array}{l}25.26 \\
(100 \%)\end{array}$ \\
\hline $\mathrm{D}$ & 0.34 & $\begin{array}{l}18.72 \\
(79.4 \%)\end{array}$ & $\begin{array}{l}4.86 \\
(20.6 \%)\end{array}$ & $\begin{array}{l}23.58 \\
(100 \%)\end{array}$ \\
\hline $\mathbf{E}$ & 0.45 & $\begin{array}{l}20.38 \\
(82 \%)\end{array}$ & $\begin{array}{l}4.39 \\
(18 \%)\end{array}$ & $\begin{array}{l}24.77 \\
(100 \%)\end{array}$ \\
\hline$F$ & 0.47 & $\begin{array}{l}20.66 \\
(79.3 \%)\end{array}$ & $\begin{array}{l}5.41 \\
(20.75 \%)\end{array}$ & $\begin{array}{l}26.07 \\
(100 \%)\end{array}$ \\
\hline$\overline{\bar{x}}$ & 0.42 & $\begin{array}{l}19.56 \\
(79.9 \%)\end{array}$ & $\begin{array}{l}4.92 \\
(20.1 \%)\end{array}$ & $\begin{array}{l}24.48 \\
(100 \%)\end{array}$ \\
\hline $\mathbf{s}$ & +0.06 & +1.13 & +0.498 & +1.43 \\
\hline
\end{tabular}


was $0.42 \mathrm{~L} / \mathrm{min}( \pm 0.06)$ with values ranging from 0.34 to $0.47 \mathrm{~L} / \mathrm{min}$. The mean exercise $\mathrm{VO}_{2}$ of $19.56 \mathrm{~L}( \pm 1.13)$ was evaluated as being representative of the aerobic energy systems contribution in the RS. Expressing the mean exercise $\mathrm{VO}_{2}$ as a proportion of the mean total $\mathrm{VO}_{2}$ [24.48L $( \pm 1.43)]$, a $4 / 5$ ths or $80 \%$ contribution was concluded.since the total $\mathrm{VO}_{2}$ value is hypothesized to represent the total energy requirement (aerobic + anaerobic) of the RS, the fractional contribution indicates that the aerobic energy system contributes approximately $80 \%$ of the energy for the RS. The recovery $\mathrm{VO}_{2}$ mean value of $4.92 \mathrm{~L}( \pm 0.498)$, considered to represent the anaerobic contribution to the RS, equates to $20 \%$ or $1 / 5$ th of the total $\mathrm{VO}_{2}$ requirement (recovery $\mathrm{VO}_{2} /$ total $\mathrm{VO}_{2}$ ). Recovery $\mathrm{VO}_{2}$ was evaluated through the oxygen consumption of the oarswomen from the end of the Rs until the pre-exercise resting $\mathrm{VO}_{2}$ level was achieved.

For calculation purposes, the $\mathrm{Vo}_{2} \max$. used for each subject was the highest $\mathrm{VO}_{2}$ recorded during the $\mathrm{RS}$ or PIT. Asterics in table II indicate the $\mathrm{VO}_{2} \max$. value used for each individual. The mean $\mathrm{Vo}_{2} \max$. of the six oarswomen, calculated with each athletes personal $\mathrm{VO}_{2} \max$. , was $3.92 \mathrm{~L} / \mathrm{min}$.

Referring to Figure 1 (absolute $\mathrm{VO}_{2}$ vs time), the oarswomen's oxygen consumption increases rapidly over the initial 2 minutes of the Rs before achieving a relatively steady level. Each subject's average $\mathrm{VO}_{2}$ during this 


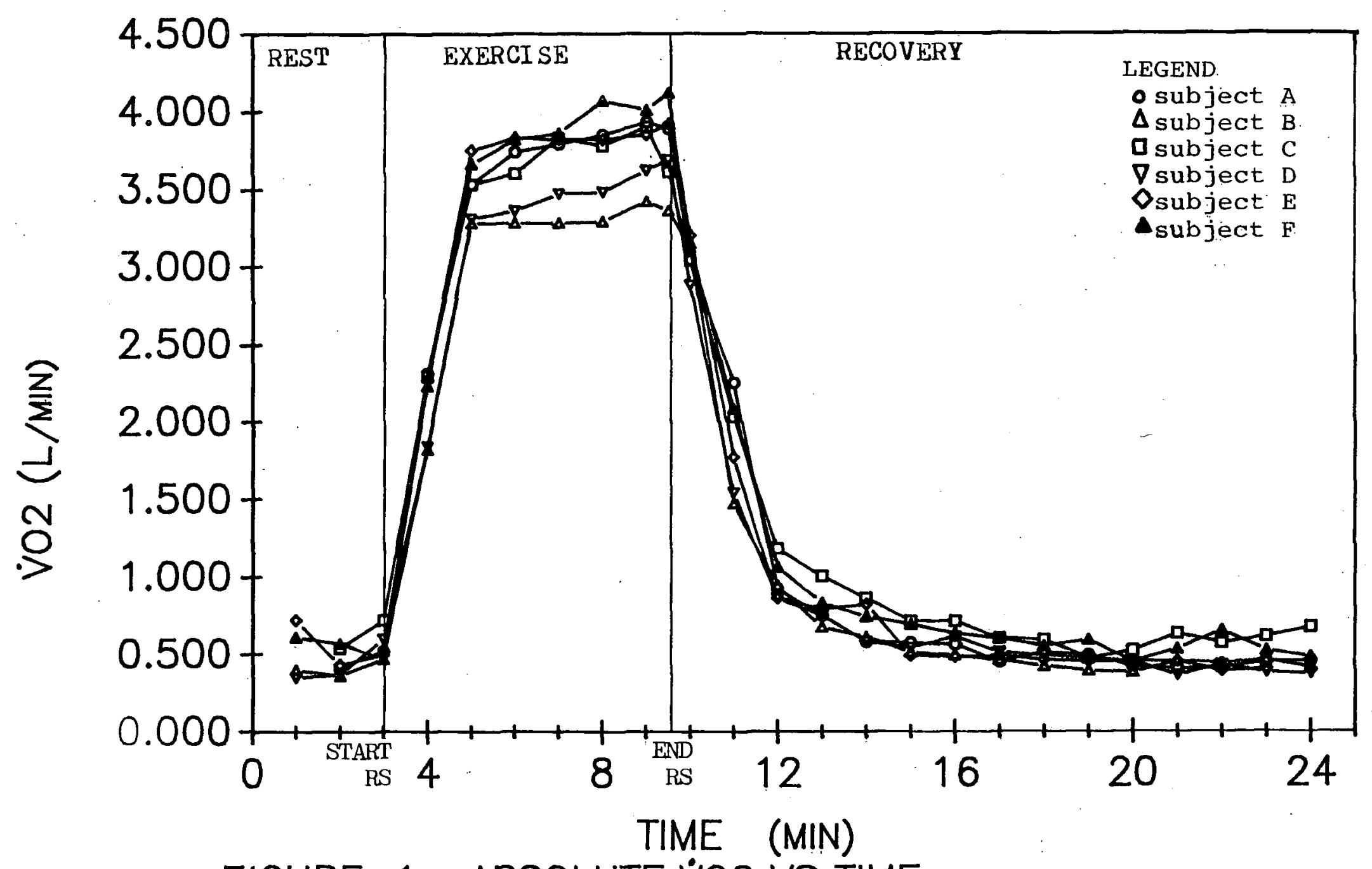

FIGURE 1: ABSOLUTE VO2 VS TIME 
steady level portion of the RS (evaluated from start of 3 rd to end of $61 / 2 \mathrm{~min}$ of $\mathrm{RS}$ ) is presented in table II. The mean value for the group was $3.71 \mathrm{~L} / \mathrm{min}( \pm 0.24)$. This race average $\mathrm{VO}_{2}$, expressed as a percentage of the groups mean $\mathrm{VO}_{2} \max .(3.92 \mathrm{~L} / \mathrm{min})$, represents an average race intensity equivalent to $94.6 \%( \pm 1.26)$ of their maximal oxygen consumption, during the final $41 / 2$ minutes. Individual average race intensities ranged from $92.48 \%$ to $95.72 \%$ corresponding to an absolute $\mathrm{vO}_{2}$ range of 3.32 to $3.98 \mathrm{~L} / \mathrm{min}$. This average race intensity implies that these oarswomen race at approximately $95 \%$ of their maximum capacity $\left(\mathrm{VO}_{2} \max .\right)$ during the last $41 / 2$ minutes of the RS. During the 3 rd to 6 th minute of the RS, the average $\mathrm{VO}_{2}$ values of the 6 subjects increased slightly each minute from $3.6 \mathrm{~L} / \mathrm{min}\left(91.9 \% \mathrm{VO}_{2} \max .\right)$ to $3.8 \mathrm{~L} / \mathrm{min}$ $\left(96.7 \% \mathrm{VO}_{2} \max .\right)$. The increases ranged from a mean of 0.04 to $0.08 \mathrm{~L} / \mathrm{min}$. In the final $1 / 2$ minute of the $\mathrm{RS}, \mathrm{a}$ an average decrease of $0.03 \mathrm{~L} / \mathrm{min}$ was evident.

Figure 2 illustrates each athletes oxygen consumption profile during the RS as a percentage of her maximal oxygen capacity (represents each oarswoman's RS profile relative to her own physiological capabilities). In figure 2 , it is evident that at 2 minutes into the RS most of the oarswomen have reached an approximate $90 \% \mathrm{VO}_{2} \max$. intensity level. In the recovery portions of figures 1 and 2 , oxygen consumption values rapidly decreased for approximately 2 1/2 minutes, immediately following the completion of the 


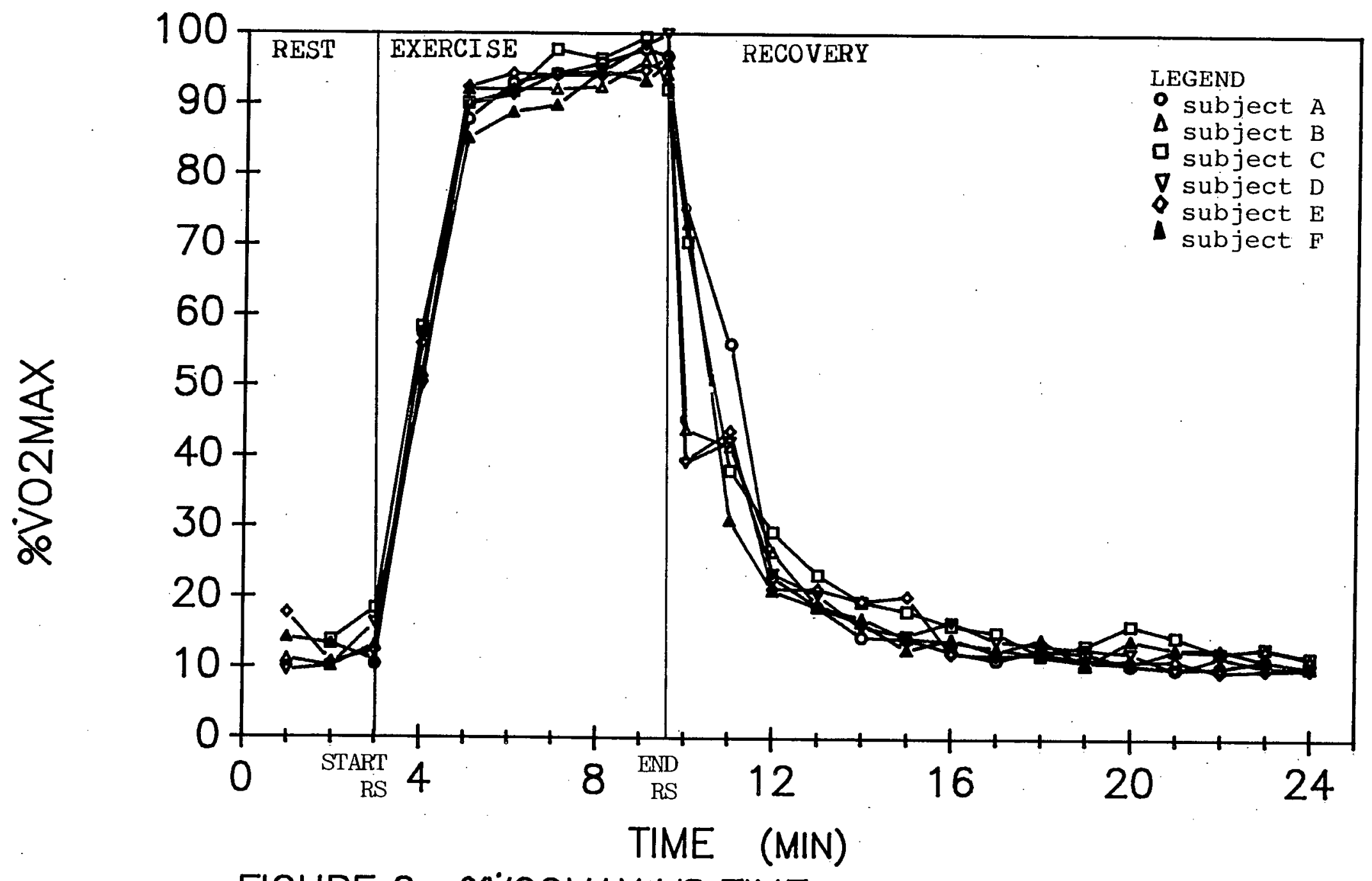

FIGURE 2: \%VO2MAX VS TIME 
RS. This rapid decline is followed by a slower decrease over the remaining recovery period to pre-test resting $\mathrm{VO}_{2}$ levels.

Heart rate (HR) profiles of the RS are illustrated in figure 3. One minute after the start of the RS, the mean HR increased to $176 \mathrm{bpm}$, equivalent to $92 \%$ of the mean max. HR. For the remainder of the RS, the heart rates gradually increased to an average maximum value of $192 \mathrm{bpm}$. Results clearly indicate a rapid adjustment of heart rates to a severe steady level which averaged 189 bpm ( \pm 4.7$)$ during the final $41 / 2$ minutes of the RS.

The response patterns of Excess $\mathrm{CO}_{2}(\mathrm{ml} / \mathrm{kg} / \mathrm{min})$ during and after the RS are presented in figure 4. The excess $\mathrm{CO}_{2}$ responses demonstrated the greatest variability between the oarswomen of any of the parameters evaluated. A hyperventilatory response at the initiation of the RS (first 30 seconds) is evidenced by the high excess $\mathrm{CO}_{2}$ levels. Following this, there was a readjustment and subsequent drop in excess $\mathrm{CO}_{2}$ over the last 30 seconds of the first minute of exercise. At the end of the first minute of exercise, excess $\mathrm{CO}_{2}$ levels rapidly increased again, attaining near maximal levels by the end of the second minute of exercise with most subjects. Throughout the remainder of the RS there was a plateauing in excess $\mathrm{CO}_{2}$ values, suggesting a steady production and elimination of carbon dioxide. At the cessation of exercise, with some individual variability, 


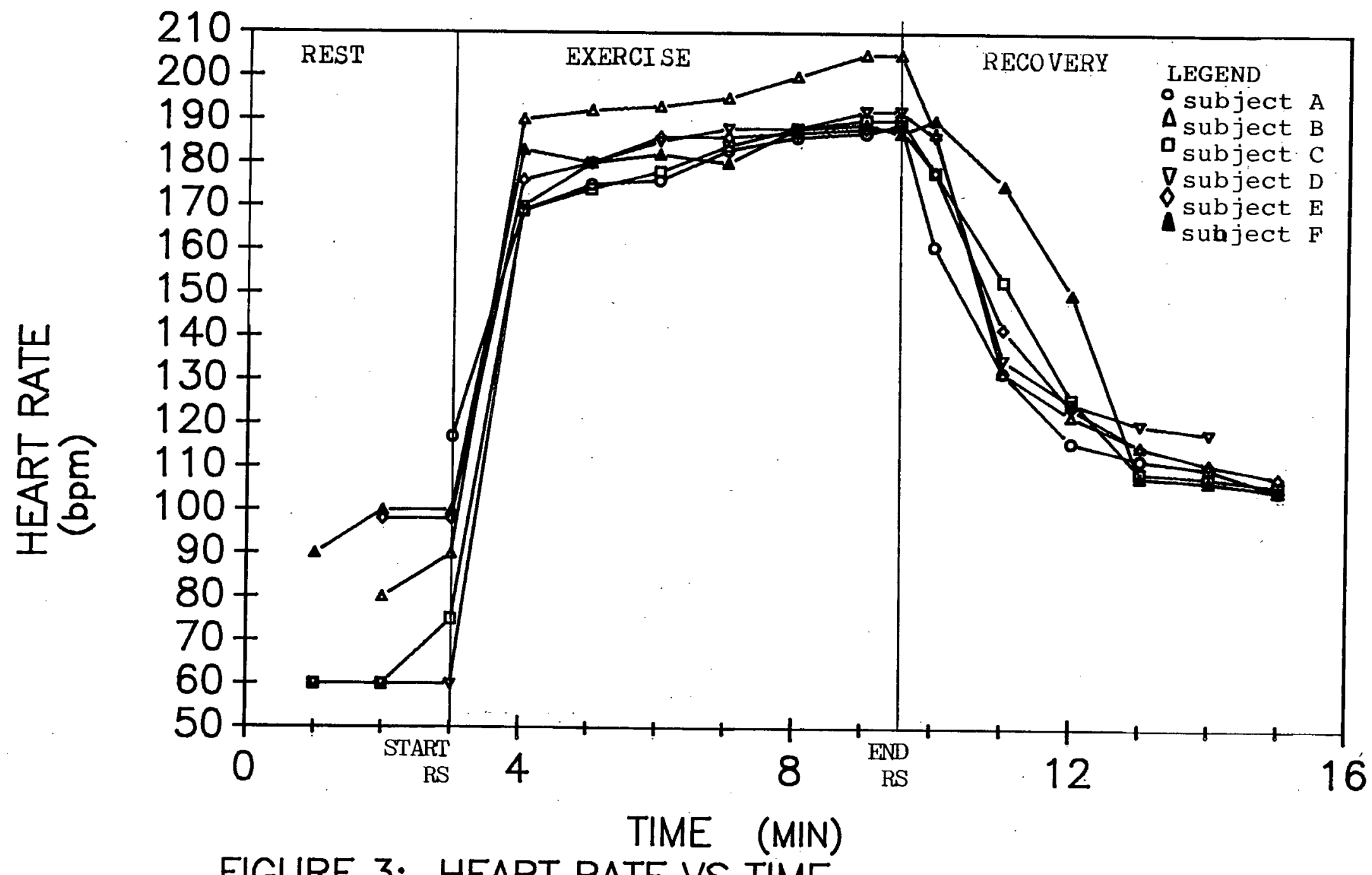

FIGURE 3: HEART RATE VS TIME 
EXCESS $\mathrm{CO} 2$

(ML/KG/MIN)

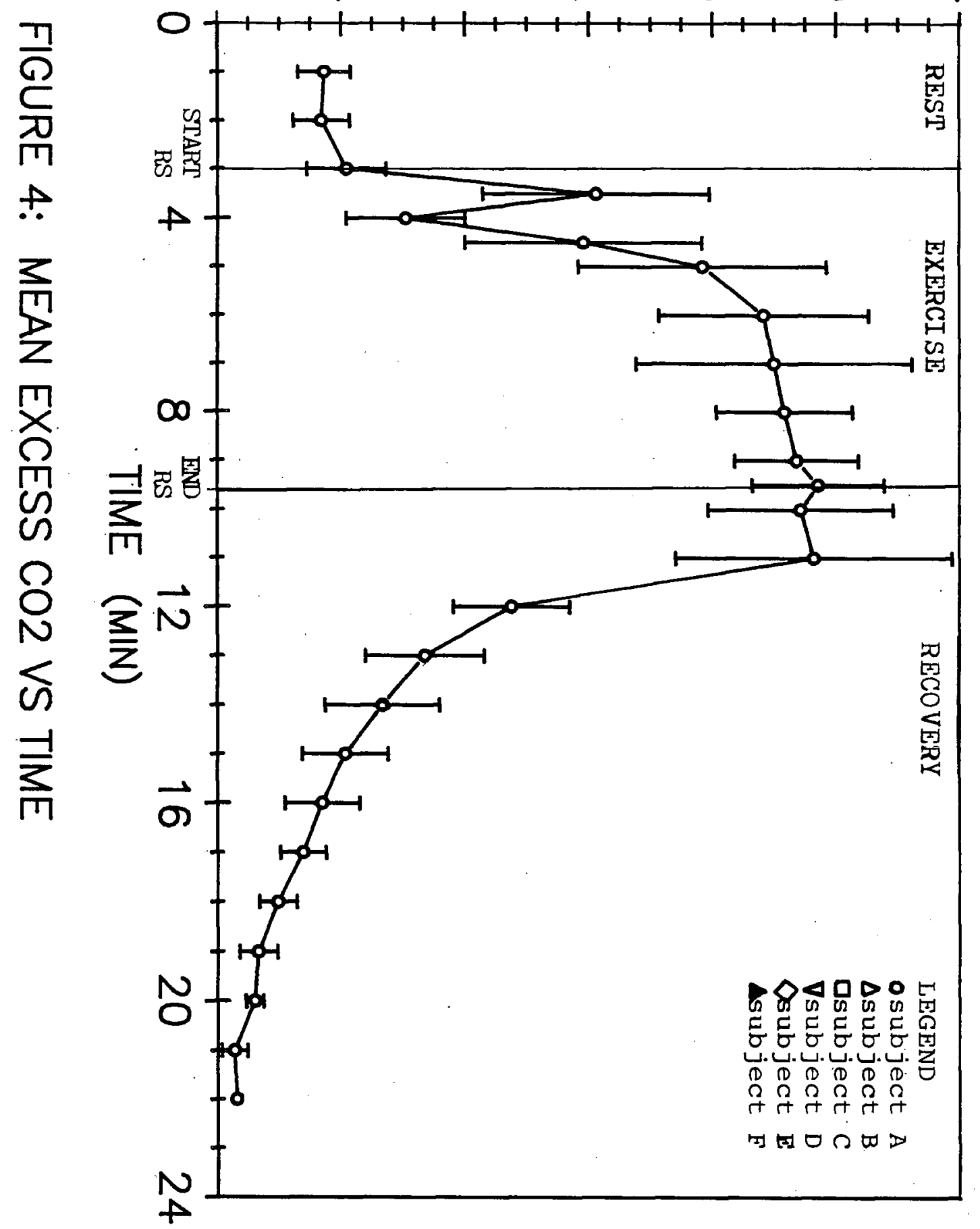


the excess $\mathrm{CO}_{2}$ recovery trend was an exponential decay for approximately $21 / 2$ minutes followed by a slow decline to below pre-exercise levels.

The ventilatory responses of the national level oarswomen evaluated, increased for the initial 2 minutes of the RS followed by a slight rise in the remaining $41 / 2$ minutes (figure 5). The mean max.VE value for the RS was $122.44 \mathrm{~L} / \mathrm{min}( \pm 11.83)$ (BTPS). Individual max.VE values represent the average of the 4 highest VE's recorded in the RS. During the final $41 / 2$ minutes, average VE values were approximately $117 \mathrm{~L} / \mathrm{min}( \pm 12.9)$, representing $90 \%$ of the max.VE for the group. Following the RS recovery profile seen in $\mathrm{VO}_{2}$, excess $\mathrm{CO}_{2}$ and $\mathrm{HR}, \mathrm{VE}$ exhibits an exponential decay and subsequent gradual tapering to pre-exercise levels.

The mean respiratory exchange ratio (RER) values recorded during the $\mathrm{RS}$ indicate a substantial elevation in the first 30 seconds (1.43) proceeded by a rapid drop in the following 30 seconds $(0.87)$. From this point, the RER climbs up again to a value greater than 1.0. For the remainder of the RS (end of the 2 nd to end of the $61 / 2$ min. of RS) a steady state RER was attained at 1.08 . In the first $21 / 2$ minutes of the recovery period, the mean RER values increase, reaching a peak of 1.47. After this peak, there is a gradual decay in the RER values. Results are illustrated in figure 6. 


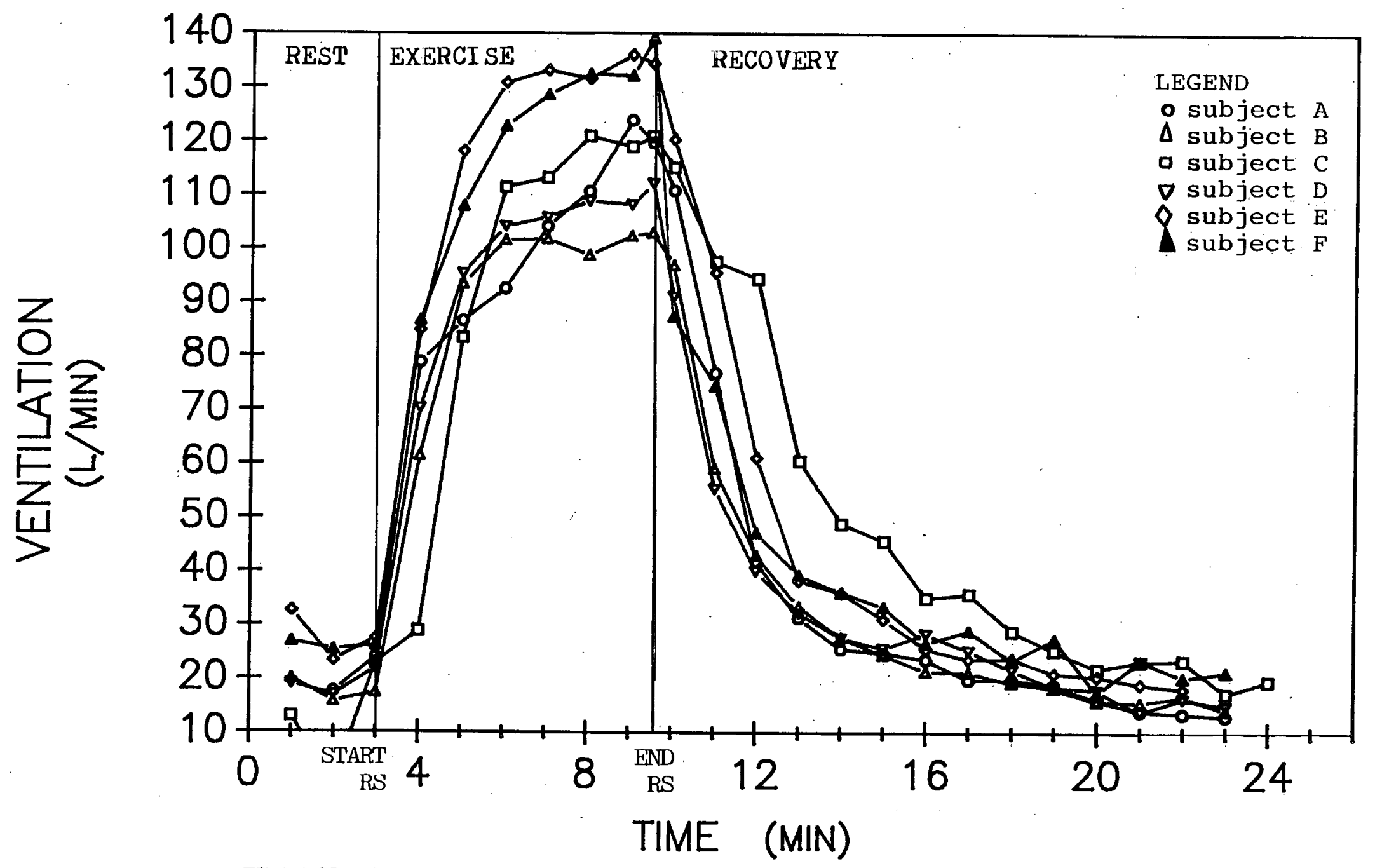

FIGURE 5: VENTILATION VS TIME 


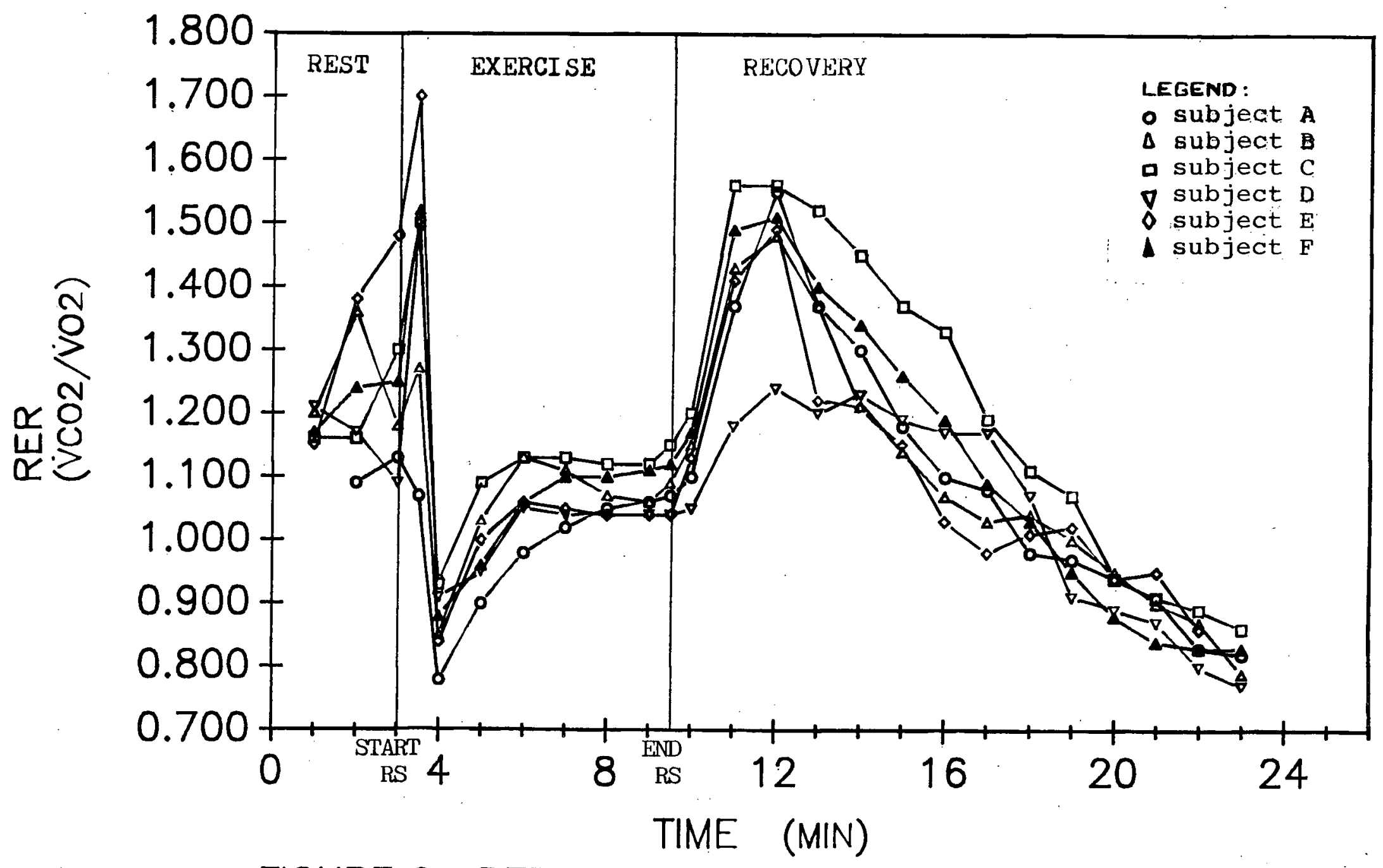

FIGURE 6: RER VS TIME 
A blood lactate profile for subject $E$, the only RS blood lactate profile available, is presented in figure 7 . Lactate levels were rapidly elevated within the initial two minutes of the RS, as was evident in VE and $\mathrm{VO}_{2} \mathrm{RS}$ responses. Subject E's blood lactates increased from 2.43 mol/l at one minute, to $5.95 \mathrm{mmol} / 1$ at the end of the second minute. At this point, blood lactates gradually plateaued. A peak lactate measure $(9.81 \mathrm{mmol} / \mathrm{l})$ was found 30 seconds after the cessation of exercise. PIT lactate profiles for subjects $B$ and $E$ are illustrated in figure 8 . Post-exercise peak values of $17.29 \mathrm{mmol} / 1$ ( $1 \mathrm{~min}$. post) and $8.93 \mathrm{mmol} / 1$ (5 min. post) were recorded for subjects $B$ and E respectively. 


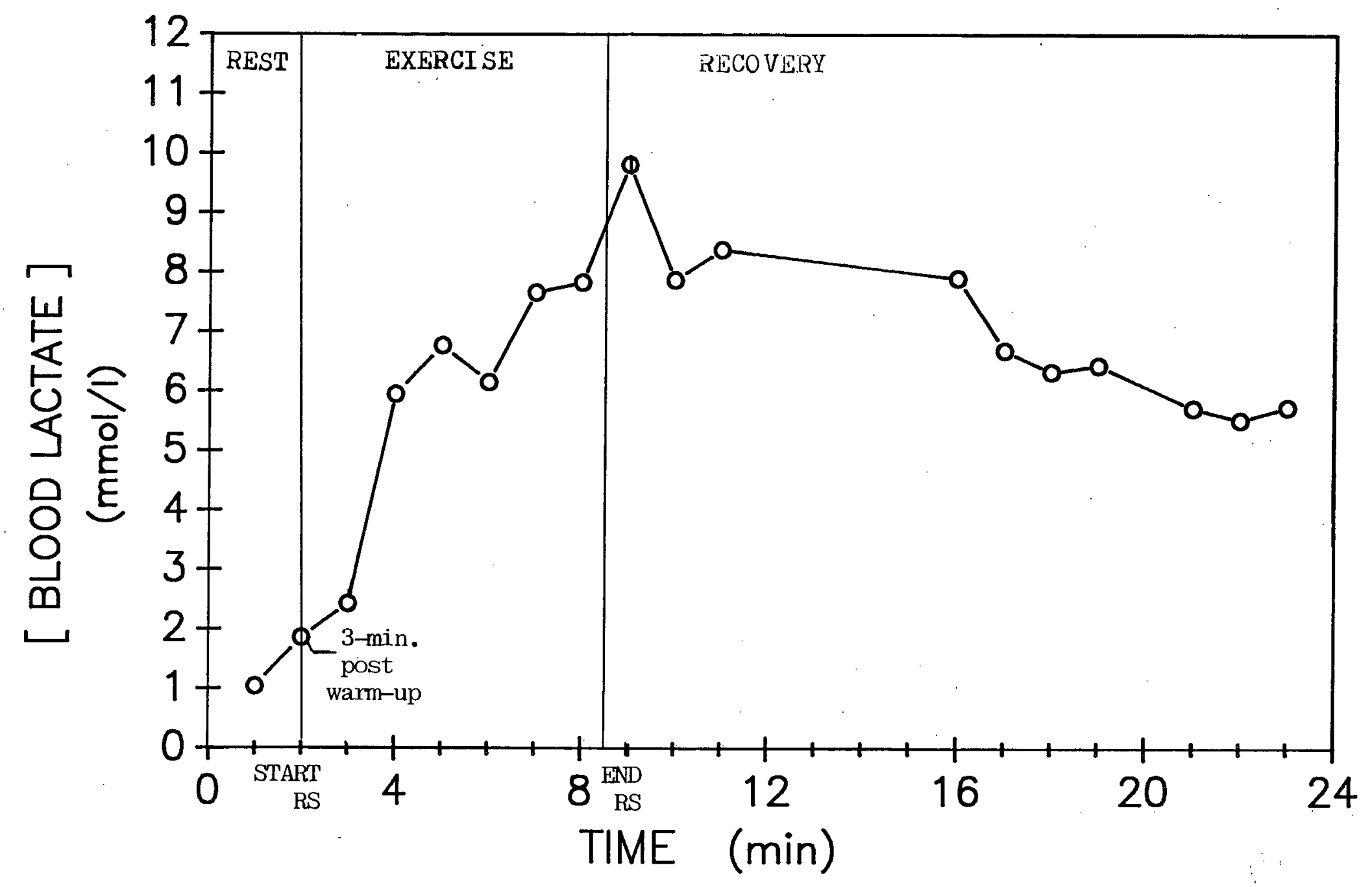

FIGURE 7: BLOOD LACTATE VS TIME (SUBJECT B) 


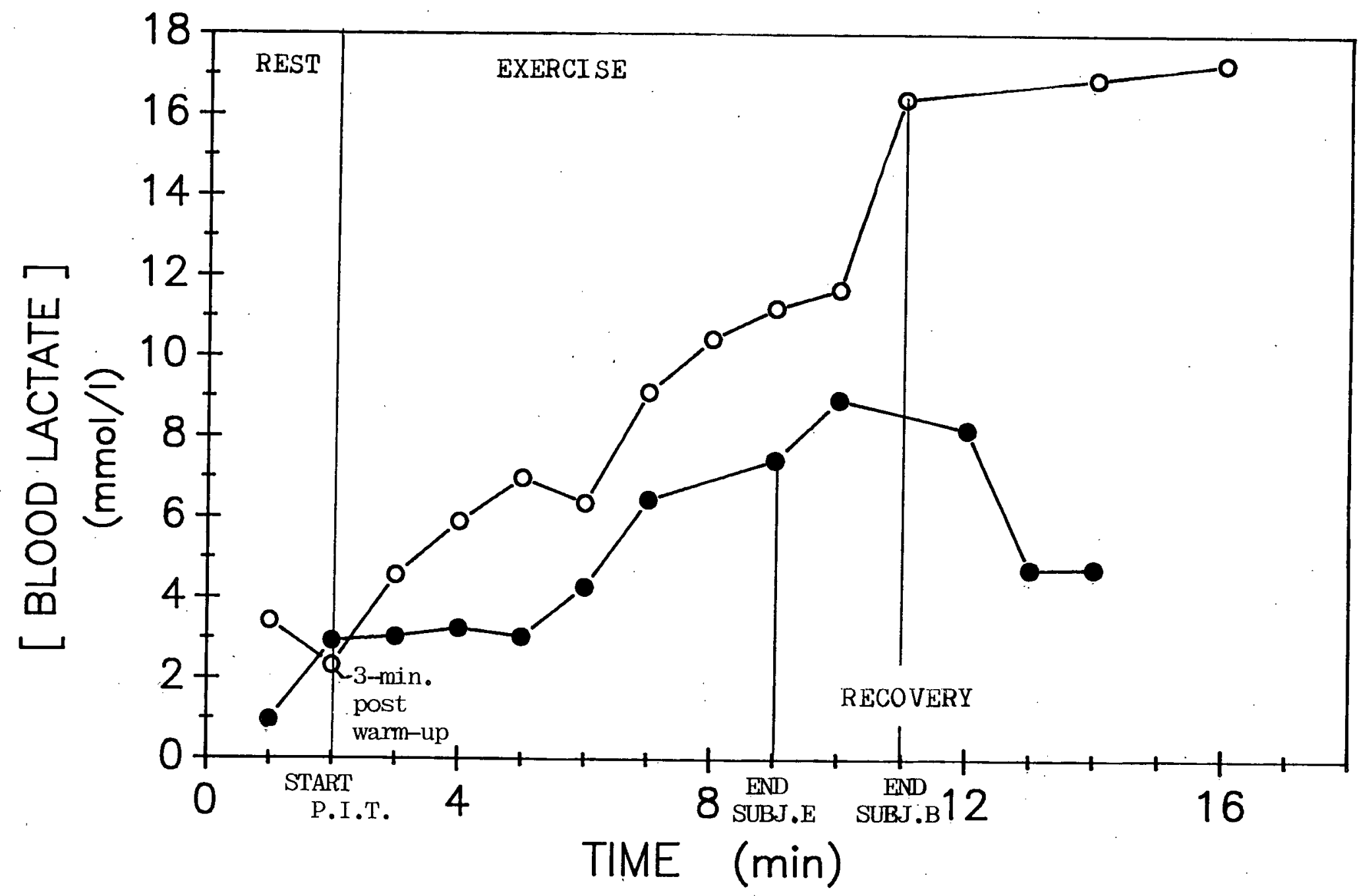

FIGURE 8: BLOOD LACTATE VS TIME (PIT - SUBJ. B \& E) 


\section{HYPOTHESIS}

1) The mean exercixe oxygen consumption for the six national level oarswomen tested is 19.56 Litres ( \pm 1.13$)$. With a total $\mathrm{VO}_{2}$ of $24.48 \mathrm{~L}( \pm 1.43)$, the average energy contribution equates to $79.9 \%$. These findings support our original hypothesis that the aerobic system supplies $80 \%$ of the energy required for national level oarswomen's execution of a 2,000 meter RS.

2) The average recovery oxygen consumption for this group of athletes was recorded as $4.93 \mathrm{~L}( \pm 0.498)$. Expressed as a percentage of the total oxygen consumption a $20.1 \%$ contribution is found. These findings support the hypothesis that the anaerobic energy system will supply $20 \%$ of the necessary energy for the 2,000 meter RS performance.

3) By approximately 2 minutes into the race simulation, the oarswomen's $\mathrm{VO}_{2} \max$. plateaued at a relatively steady state level. The average $\mathrm{VO}_{2} \max$. percentage during this plateau was $94.6 \%( \pm 1.26)$. These values are calculated from each oarswoman's exercise $\mathrm{VO}_{2}$, as averaged from end

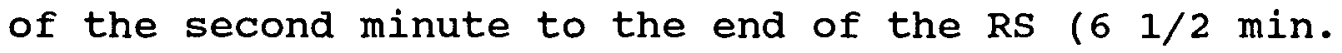
mark). Individual values ranged from $92.5 \%$ to $95.7 \%$ of $3.32 \mathrm{~L} / \mathrm{min}$. to $3.98 \mathrm{~L} / \mathrm{min}$. . 
$-69-$

DISCUSSION 


\section{PHYSICAL CHARACTERISTICS}

It is difficult to develop a profile on the physical attributes of oarswomen (national level or otherwise) due to the paucity of literature examining these athletes. Hebbelinck, M. et.al.(1981) examining 51 oarswomen at the 1976 olympics concluded that these athletes tend to be taller and heavier than those in a non-athletic and Canadian university female student sample. The mean height and weight of their oarswomen was $174.3 \mathrm{~cm}( \pm 4.71)$ and 67.4 $\mathrm{kg}( \pm 5.28)$. Hagerman, et.al.(1979) and Mahler, et.al.(1985) evaluating elite and Collegiate level oarswomen respectively report average body weights of 68 to $70 \mathrm{~kg}$ and average heights of 172 to $173 \mathrm{~cm}$. These researchers further supported Hebbelinck's conclusion that oarswomen tend to be lean tall athletes. The national level oarswomen involved in this research presented a larger body weight average and a greater height average than has preiously been reported. Recruiting tends to focus on the taller muscular individuals, based on the belief that these body types are best suited for the biomechanical and physiological demands of the sport, which may partially explain the physical consistencies.

\section{RACE SIMULATION}

Attempts have been made in the past to evaluate the 
energy demands and cardiorespiratory responses of rowing on on oarsmen, both on and off the water (Carey, et.al., 1974; Hagerman, et.al., 1972; Jackson \& Secher, 1976; Mickelson \& Hagerman, 1982; Secher, 1983b; Steinacher, et.al., 1983; Williams, 1976). The on-water research does not allow the sophisticated and detailed analysis that the laboratory evaluations do.

The mean $\mathrm{VO}_{2} \max$. measured in the $\mathrm{RS}$ was $3.85 \mathrm{~L} / \mathrm{min}$ $( \pm 0.24)$, a value not significantly different from that reported in the P.I.T. $(3.89 \mathrm{~L} / \mathrm{min}( \pm 0.27))(p>.01)$. Relative to earlier data on elite and collegiate oarswomen, our results are approximately mid-range. Hagerman, et.al.(1979), reported a mean peak $\mathrm{vo}_{2}$ for elite oarswomen of $4.1 \mathrm{~L} / \mathrm{min}( \pm 0.4)$ in a 3 -minute RE test. Later, Young and Rhodes (1985), examining collegiate oarswomen in a 7 -minute $\mathrm{RS}$ test found a mean $\mathrm{VO}_{2} \max$. of $3.51 \mathrm{~L} / \mathrm{min}( \pm 0.2)$. Considering the different calibre of athlete tested in these studies and the inclusion of a lightweight rower in the 1985 sample, the range in $\mathrm{VO}_{2} \max$. is not surprising.

\section{RECOVERY OXYGEN ANALYSIS}

Recovery oxygen analysis involves measuring the difference between resting $\mathrm{VO}_{2}$ of a recovery period and post-exercise $\mathrm{VO}_{2}$ for that same period (Keele, et.al., 1982). The measurement of this variable is believed to 
reflect the magnitude of anaerobic energy stores available during muscular work (Welch, et.al., 1970). The oxygen consumption during the recovery phase (excess post-exercise oxygen consumption) is hypothesized to restore muscle phosphagen and glycogen stores, replenish myoglobin with oxygen, and remove lactic acid from muscle and blood (Fox, 1979). However, excess post-exercise oxygen consumption is a very complex mechanism ( Brooks \& Fahley, 1984) and there are several other factors which may elevate $\mathrm{VO}_{2}$ during recovery. Some of these factors include, hyperventilation, metabolite turnover and synthesis, and ion redistribution $\left(\mathrm{Na}^{+}, \mathrm{Ca}^{+}, \mathrm{K}^{+}\right)$(Stainsby \& Barclay, 1970). Despite of the possible limitations of measuring recovery $\mathrm{VO}_{2}$ and using it in anaerobic metabolism analysis, excess post-exercise oxygen consumption is still the best available method for estimation of the RS anaerobic component at this time.

other methods used in the estimation of the anaerobic systems contribution include oxygen deficit and blood (or muscle) lactate analysis. Computation of the anaerobic component through oxygen deficit calculations is not appropriate in this study since there is no clear steady state level during the $\mathrm{RS}$ from which a required $\mathrm{VO}_{2}$ could be estimated. Without a computed oxygen requirement for the RS, the oxygen deficit equation cannot be solved (Brooks \& Fahley, 1984). Attempts to assess the anaerobic component of an exercise bout from post-exercise blood or 
muscle lactate concentrations are also questionable given the possible difficulties in determining the distribution volume for lactate (Margaria, et.al., 1963).

\section{AEROBIC CONTRIBUTION}

The aerobic energy system's contribution to a 2,000 meter RS for national calibre oarswomen is approximately $80 \%$ or $4 / 5$ th's of the total energy requirement. This high fractional aerobic contribution indicates the tremendous aerobic demand of the 2,000 meter race simulation (RS) (calculations based on Devries, 1986 (see appendix)). In the 1,000 meter race, the oarswoman's aerobic energy system supplied somewhere between 55\% and 65\% (up to 3/5th's) of the total energy (Mahler, et.al., 1984; Hagerman, et.al., 1979; Hagerman, 1984), understandably lower than the 2,000 meter RS. Since similar contributions of aerobic/anaerobic metabolic pathways for maximal exercise of comparable durations have been reported (Astrand \& Rodah1, 1977; Berger, 1982), the energetics exhibited in the 2,000 meter RS were expected.

There is a definite lack of research pertaining to oarswomen racing over $1,000 \mathrm{~m}$. At the $2,000 \mathrm{~m}$ distance there is presently only one other known study involving oarswomen (Young \& Rhodes, 1986). Consequently, to advance this analysis, data from research on oarsmen rowing 2,000m ( 6 min.) on a (RE) (Hagerman, et.al., 1975; Mahler, et.al., 
1984), and from oarswomen rowing a 2,000 meter RS (7 min.)(Young \& Rhodes, 1986) were reviewed.

Young and Rhodes (1986) reported an $84 \%$ aerobic contribution in a 7-minute RS with collegiate oarswomen. Considering the slightly greater exercise duration ( 30 seconds) (ie. lower calibre of athlete tested, ie. longer race duration), these results appear to be comparable to the present findings. Both studies evaluated the aerobic energy (NET $\mathrm{O}_{2}$ INTAKE) component by employing the formula of Devries (1986)(see appendix). Some of the data available on oarsmen executing a 6 minute RE test suggests that $70 \%$ to $78 \%$ of the energy contribution is supplied by the aerobic energy system (Hagerman, 1975; Hagerman, et.al., 1979; Mahler, et.al., 1984). In comparison to the oarswomen, male rowers incorporate a smaller fraction of their aerobic energy system to meet the high metabolic demands of the shorter 6-minute RE test.

The oarsmen and oarswomen are able to maximally tax aerobic system in the $2,000 m$ race (evidenced by the $95 \%$ $\mathrm{VO}_{2} \max$. race intensity) by incorporating an unusual pacing strategy (Hagerman, et.al., 1972). The race commences with a sprint, at a high stroke frequency or rate, lasting approximately 50 seconds to 1 minute (250m on water). The sprint start is executed in an attempt to advance the crew into the lead enabling the rowers to see their competitors (ie. psychological benefit). Secher, et.al.(1976), as referenced by Astrand and Rodahl (1977), 
found that the large energy expenditure early in a 6-minute simulated race on a bicycle ergometer lead to a more rapid increase in oxygen uptake then when sprint start is not performed. During the final $250 \mathrm{~m}$ or 1 minute of the $2,000 \mathrm{~m}$ race, another sprint is executed in an attempt to elevate the boat speed. Considering the high level of energy output the athlete is working at $\left(95 \%\right.$ of $\mathrm{VO}_{2}$ max.), a further increase in output stimulates production of any remaining fraction of possible energy from the aerobic and anaerobic systems (primarily from the anaerobic system, Fox (1979)) .

\section{ANAEROBIC ENERGY CONTRIBUTION}

In the first two minutes of the race simulation, while the athlete's aerobic system attempts to meet the body's energy requirements, the anaerobic system (alactic/lactic) provides a large part of the energy needed (Keul, J., 1973). This stage requires substantial output from the anaerobic system. A consequence of this early anaerobic (maximal) contribution is a rapid elevation of blood \& muscle lactate levels, ultimately resulting in muscular fatigue. An estimation of the anaerobic system's contribution to the RS (with acknowledged linitations) was made through the evaluation of the recovery oxygen uptake $\left(\mathrm{VO}_{2}\right)$ during the post-exercise period of the RS (referred to as excess 
post-exercise oxygen consumption). The excess post-exercise oxygen consumption of the oarswomen's RS was approximately $4.92 \mathrm{~L}(+0.498)$ or $20 \%$ of the total oxygen uptake. (These values were based on calculation procedures of Devries (1986) (see appendix B\}). Comparatively, Young and Rhodes (1986) reported a mean recovery oxygen consumption of $4.18 \mathrm{~L}( \pm 1.43)$ for collegiate oarswomen performing a 7-minute RS, using the same Devries (1974) calculation methods.

In contrast to these reports, Hagerman, et.al.(1978), found a mean oxygen debt value of $13.4 \mathrm{~L}( \pm 6.3)$ for oarsmen performing a 6-minute RE test. Later, in 1979, a mean oxygen debt value of $10.2 \mathrm{~L}( \pm 5.5)$ was reported for oarswomen in a 3-minute RE test by Hagerman, et.al., using an exercise $\mathrm{VO}_{2}$ baseline for oxygen debt analysis. These values, proposed to be representive of absolute anaerobic contribution, are substantially larger than the national level oarswomen's evaluated here. The procedures followed for evaluating the recovery $\mathrm{VO}_{2}$ (to estimate the relative anaerobic contribution) are not provided in the literature (Hagerman, et.al., 1978 \& 1979), preventing clarification of the discrepant values between the studies. The oxygen debt values for maximal exercise lasting from 4 to 6 minutes have been found to be approximately the equal (Whipp, et.al.,1970). Consequently, the discrepancy in the present results and Young and Rhodes (1986) with those of Hagerman, et.al.(1978 \& 1979), is unlikely simply 
the result of variability in exercise duration (ie. exercise being of maximal intensity). It is possible that these discrepancies are a consequence of an inappropriate evaluation of the recovery oxygen consumption. Furthermore, secher (1983) states that oxygen debt values are smaller in beginners than in well-trained oarsmen. This implies that the caliber of the athlete may account for the differences seen.

\section{RACE SIMULATION INTENSITY}

Calculation of the racing intensity level of the national calibre oarswomen involves representing an absolute $\mathrm{VO}_{2}$ value as a percentage of an absolute $\mathrm{VO}_{2} \max$. value. Two minutes after the RS started, five of the six oarswomen achieved an intensity level demanding more than a $90 \%$ contribution from the aerobic systems maximum capacity. These findings are indicative of a high level of oxygen utilization. The time required to achieve a high steady level $\mathrm{VO}_{2}$ during the men's 6-min. RE test is approximately 2 minutes after the start (Mahler, et.al., 1984). Support for these earlier findings is provided by the approximate $92 \%$ mean $\mathrm{VO}_{2}$ max. recorded at the end of the second minute of the present RS.

The average intensity of exertion (from end of 2 nd min. to end of $61 / 2 \mathrm{~min}$.) in the RS is equivalent to approximately $95 \%( \pm 1.26)$ of the mean $\mathrm{VO}_{2} \max$. . 
Comparatively, Young and Rhodes (1986) reported a $96 \%$ mean $\mathrm{VO}_{2} \max$. intensity level during the final $41 / 2$ minutes of a 7-minute RS for collegiate oarswomen. Oarsmen evaluated in a 6-minute RE test, exercised at an intensity level equivalent to $96 \%-98 \%$ of mean $\mathrm{VO}_{2} \max$. in the final portion of a rowing test (Bouchant, et.al.,1983 \& Hagerman, et.al.,1978). The present results clearly agree with those of earlier research. Examination of race intensity in relative percentages allows comparisons between experience levels of the oarsmen and oarswomen to be made.

Rowing on an ergometer may be somewhat similar to intermittent work since athletes usually row at 32 to 36 spm (Carey, et.al. 1974). Comparatively, running is considered to be a continuous type of work (Carey, et.al.,1974). Cunningham, et.al.(1975), hypothesize that although work rate is dependent on number of revolutions of the flywheel, it is independent of the number of strokes rowed per minute. All 6 of the present subjects raced with the same tape recorded race simulation (stroke rate calls, commands, etc.), providing minimal variability in the stroke ratings from one athlete to another. Stroke rates ranged from approximately 32 to 35 spm during the steady state portion of the RS. Considerable subject variability was found in the number of flywheel revolutions during the RS. Work rate, hypothetically dependent on the number of flywheel revolutions (Cunningham, et.al.(1975)), is definitely variable in the RS. The range of average 
flywheel revolutions per minute in RS was from 506 to 617 .

\section{HEART RATE}

Heart rate measures are a valuable tool for evaluation and monitoring of an individual's exercise intensity. Maximal heart rates are identified when, with a continued increase in workload there is no further increase in HR. The average maximal heart rate (bpm) for both the RS and PIT was approximately $193 \mathrm{bpm}$ (RS $= \pm 6.43$ \& $\mathrm{PIT}= \pm 8.04)$. There is a rapid increase in $\mathrm{HR}$ at the inititation of RS as the body adjusts to meet the demands placed upon it. By the completion of the second minute of the RS, mean HR attains a high steady state levels and continues to rise by approximately $2 \%$ each minute until the completion of the RS. These results closely resemble the findings of Young and Rhodes (1986). In their study with collegiate oarswomen maximal RS heart rates were $186 \mathrm{bpm}$. The heart rate profile they reported indicated a rapid increase with the initiation of the RS with a plateauing at the end of the second minute. The present findings verify the maximal demands of the RS on the cardiac functioning.

\section{$\underline{\operatorname{EXCESS} \mathrm{CO}_{2}}$}

Measurement of excess $\mathrm{CO}_{2}$ serves as a possible indicator of the magnitude of glycolytic production of 
lactate through glycolysis (Volkov, et.al., 1975). Furthermore, excess $\mathrm{CO}_{2}$ reflects the state of the buffer reserves of the athlete (Volkov, et.al.,1975). In evaluating the energy demands of the $61 / 2$ minute RS, excess $\mathrm{CO}_{2}$ data was analyzed as a possible representive of the percentile participation of anaerobic processes in total energy expenditure. Figure 4 (excess $\mathrm{CO}_{2}$ vs time) illustrates the definitive involvement of the anaerobic energy system during the RS. In the first 30 seconds of this severe steady state exercise, there is an abrupt increase in excess $\mathrm{CO}_{2}$ as a result of hyperventilation (increase in lung ventilation rate beyond that needed for existing metabolic rate (Devries, 1986\}). Within the following 30 seconds (last $1 / 2$ of first minute) excess $\mathrm{CO}_{2}$ drops (approx. $1 / 2$ of level it was in initial 30 seconds) because the hyperventilation outstrips the metabolic $\mathrm{CO}_{2}$ production (Devries, 1986). During the second minute of the RS, excess $\mathrm{CO}_{2}$ increases again and continues to increase, reaching a plateau near the end of the third minute. This response is the body's attempt to deal with the increase in carbon dioxide that is being produced in part by the buffering of the lactic acid being produced by the muscles. (The anaerobic threshold has been exceeded after the first minute of the RS necessitating the continual involvement of the anaerobic system throughout the exercise.) A plateau in excess $\mathrm{CO}_{2}$ is achieved when a constant level of lactic acid production and removal (no 
further increase in rate of lactic acid production) is reached, therefore, the $\mathrm{CO}_{2}$ produced through buffering becomes constant. The elevated excess $\mathrm{CO}_{2}$ level is thought to indicate the magnitude of lactate production via glycolysis, and the state of the buffer reserve of the individual (Mackenzie \& Rhodes, 1983).

\section{VENTILATION $\left(\mathrm{V}_{\mathrm{E}}\right)$}

There is no one single factor that can be held fully accountable for the ventilatory response to exercise. Consequently, much of the ventilatory response is unexplained (Levitzky, M.G., 1982). A great deal of controversy surrounds the mechanisms involved in the increase in ventilation seen in muscular work (Astrand \& Rodahl, 1977). In spite of these problems, the ventilatory response to exercise is acknowledged as an excellent index of the ability of the body's gas transport mechanisms to meet the cellular oxygen requirements (Wasserman, K., 1978). Furthermore, $V_{E}$ may reflect metabolic acidosis and level of cardiovascular fitness (Wasserman, et.al., 1973).

For the initial two minutes of the race simulation, the oarswomen's $V_{E}$ increased markedly from $77.59 \mathrm{~L} / \mathrm{min}$ to $102.1 \mathrm{~L} / \mathrm{min}$ (measured at the end of the 1st \& 2nd min. respectively). In the remaining $41 / 2$ minutes, the ventilation plateaued at an average of $116.9 \mathrm{~L} / \mathrm{min}$ (BTPS) 
(averages ranged from 101.5 to $133.2 \mathrm{~L} / \mathrm{min}$ ). This average plateau value represents $95 \%$ of the mean RS max. $V_{E}$ (as measured during RS) and $90 \%$ of the mean max. $v_{E}$ reached in the P.I.T.. The apparent delay in reaching this plateau is a result of a necessary adjustment period for the body. Davies, et.al.(1972), indicate that $V_{E}$ increases at a slower rate when an individual moves from rest to heavy work, then when moving from rest to light work. Wilmore (1979) hypothesizes that the more intense the exercise, the more time it will take to achieve a steady state or plateau (Secher (1976), in Astrand \& Rodahl, 1977).

The elevation in ventilation during exercise is a result of the necessity to supply oxygen and eliminate the metabolic waste product of $\mathrm{CO}_{2}$. At the cessation of exercise, ventilation values exhibit an exponential decay. Within 30 seconds of the end of the race, ventilations dropped to $82 \%$ of the RS mean max.Ve. By the $11 / 2$ minute mark, post RS, the $V_{E}$ dropped to $62 \%$ of the RS mean $\max \cdot \mathrm{v}_{\mathrm{E}} \cdot$

The current findings provide no indication of a pulmonary $\left(V_{E}\right)$ impairment. Many other researchers have also found no evidence to support the occurence of any impairment or restriction (Bouchant, et.al., 1983; Hagerman, et.al., 1971; Hagerman, et.al., 1978; Mahler, et.al., 1987). Cunningham, et.al.(1975), hypothesized that a reduced ventilatory ratio, $\mathrm{v}_{\mathrm{E}} / \mathrm{VO}_{2}$ during simulated rowing is primarily due to the cramped 
body position of the oarsman at the catch (start) of the stroke cycle. It was thought that the sudden forceful effort at the catch may induce a valsalva maneuver effect which would reduce venous return and cardiac output, thereby reducing the oxygen consumption. However, without any other support for this hypothesis pulmonary impairment cannot be substantiated.In 1979, Hagerman, et.al., testing elite oarswomen in a 3 -minute test on a $\mathrm{RE}$ reported $\max . \mathrm{v}_{E}$ values of $165 \mathrm{~L} / \mathrm{min}( \pm 15.6)$ (BTPS). Young and Rhodes (1986) found lower values with a collegiate group, the mean max. $\mathrm{V}_{\mathrm{E}}$ being $138.6 \mathrm{~L} / \mathrm{min}( \pm 13.22)$ (BTPS) in a 7-minute RS.

The range of $\mathrm{V}_{\mathrm{E}}$ 's previously reported can be expanded further by examining the recorded mean max. $v_{E}$ of $113 \mathrm{~L} / \mathrm{min}( \pm 17)$ (BTPS) of Rosielli, et.al.(1987). This 1987 study involved a P.I.T. on a concept II rowing ergometer, and female subjects with a tremendous range in ability and experience in rowing. With the results of the present study reporting a mean max. $\mathrm{v}_{E}$ of $122.4 \mathrm{~L} / \mathrm{min}$ $( \pm 11.8)$ (BTPS) in the RS and $129.99 \mathrm{~L} / \mathrm{min}( \pm 11.1)$ (BTPS) in the P.I.T., discrepancies in the literature are quite evident. The results of Rosiello, et.al.(1987), probably reflect a lack of experienced rowing subjects, indicated by the very low mean maximal ventilations. Comparing data from RE tests of different durations (ie. $3,4,61 / 2 \& 7$ min.) and subject pools (ie. experience), inconsistencies in physiological measures are to be expected. A shorter 
test may be executed with the same intensity $\left(\% \mathrm{VO}_{2} \max .\right)$ but peak or maximum responses (ie. $\mathrm{V}_{\mathrm{E}}$, excess $\mathrm{CO}_{2}$ ) may be higher. In the longer tests, a high steady level of output must be maintained for a few minutes, while in the shorter tests no steady level is achieved. For example, the ventilatory responses of the present study reach maximal levels at approximately 2 minutes into the RS which, in a 3-minute RE test, would be equivalent to the point at which the oarswoman begins her sprint for the finish (probably further elevating her $V_{E}$ ) (Wasserman, 1978).

\section{BLOOD LACTATE}

An attempt to catheterize each oarswoman for blood lactate analysis in the RS was unsuccessful. Placement of a catheter was only successful in 3 of the 6 subjects involved. Unfortunately, of the six sample sets collected only three rendered any meaningful results. Due to possible insufficient mixing of blood in the collection vials (containing hemolyzing agent), anaerobiosis continued following blood removal, falsely inflating the blood lactates measured. With only one RS and two P.I.T. blood profiles, no justifiable conclusions can be made.

The RS blood profile did follow a similar pattern to the oarsmen's in the studies of Mackenzie and Rhodes (1982) and Hagerman, et.al., (1978). A rapid elevation was 
evident in the first 2 minutes $(2.43 \mathrm{mmo} / \mathrm{L}$ (1st. min.) to $5.95 \mathrm{mmol} / \mathrm{L}$ (end of 2 nd min.)), followed by a steady upward plateauing to a $7.1 \mathrm{mmol} / \mathrm{L}$ level. Within $11 / 2$ minutes post-RS, lactates began to gradually decline. A peak lactate value was measured 30 seconds post-RS (9.81 mol/L). With the rapid decline in lactates post-exercise, as seen in our subject and the oarsmen of Mackenzie and Rhodes (1982), it appears that the athletes high level of training may enable them to oxidize lactic acid within the skeletal muscle (Mackenzie \& Rhodes, 1982). The exercise itself may provide a sort of oxidizing of lactate during the test period. Hagerman, et.al. (1978), hypothesized that glycolysis diminishes after a steady state is attained and the lactic acid accumulated thus far remains constant unless the exercise intensity increases.

The P.I.T. lactate values of the two subjects recorded show substantial individual variation. One subject peaked at $8.93 \mathrm{mmol} / \mathrm{L}$ at 1 minute post-exercise. Both subjects profiles in the P.I.T. followed a gradual elevation during the exercise, but again exhibited quite different post-exercise recovery patterns. Without any other data, it would be pointless to attempt further analysis or explanation.

\section{RESPIRATORY EXCHANGE RATIO}

"The respiratory exchange ratio (RER) is a ratio of 
the rate of $\mathrm{CO}_{2}$ output to the rate of $\mathrm{O}_{2}$ uptake by thelungs during a given period of time."(Slonim \& Hamilton, 1981). At the start of exercise, the RER increases as a consequence of the hyperventilation that preceeds the achievement of a steady state. During exercise, with the development of a metabolic acidosis, there is an increase in $\mathrm{CO}_{2}$ output (disproportionate to the increase in $\mathrm{O}_{2}$ uptake) and a subsequent increase in RER. Exercise eliciting $\mathrm{VO}_{2} \max$. is reported to result in RER values of 1.0 to 1.4 with a mean of approximately 1.15 (Mole, P.A., 1983) leading to the notion that CHO utilization is dramatically elevated with increased exercise intensity (especially above the lactate threshold).

A rapid increase and rapid decrease in $R E R$ values are evident within the first 60 seconds of the RS (fig. 6). The initial increase to 1.43 is indicative of the hyperventilatory response to the exercise, which increases $\mathrm{CO}_{2}$ output exhalation disproportionately from $\mathrm{VO}_{2}$. The following decrease to 0.87 in the last half of the first minute is the result of ventilation outstripping $\mathrm{CO}_{2}$ production prior to the attainment of a steady state. In the remaining minutes of the RS, RER increases to reach a steady state level at an RER of 1.08 , falling within the exercise RER range predicted by Mole (1983). On cessation of exercise, RER values in RS increase for the first $21 / 2$ minutes to reach an average peak of 1.47 , before gradually decaying. This post-exercise increase is 
induced by a continued high $\mathrm{CO}_{2}$ output indicative of lactic acid metabolism, while oxygen uptake drops, inflating the RER. 
$-88-$

CHAPTER FIVE

SUMMARY \&

RECOMMENDATIONS 


\section{SUMMARY \& RECOMMENDATIONS}

The aerobic/ anaerobic contribution in a 2,000 meter race simulation for national level oarswomen appears to be $80 \%$ and $20 \%$ respectively. The level of intensity at which these oarswomen can execute the $61 / 2$ minute, 2.000 meter race simulation is equivalent to approximately $95 \%$ of their $\mathrm{VO}_{2} \max . \quad\left(\mathrm{VO}_{2} \max\right.$. being the highest $\mathrm{VO}_{2}$ value recorded for each subject in either the PIT or RS on the Gjessing ergometer).

The current study provides an analysis of the bioenergetics of the 2,000 meter race simulation for national level oarswomen. Based on the present findings the energy requirements of an actual "on-water" race can confidently be predicted. With an $80 \%$ aerobic and $20 \%$ anaerobic energy contribution, the athlete's maximal oxygen capacity is a significant performance factor at the 2,000 meter race distance. Obviously, with the increased aerobic energy component in the 2,000 meter versus the 1,000 meter race, it is necessay to modify old training programs.

The oarswomen race for approximately $61 / 2$ minutes (in an eight), and spend between $41 / 2$ and 5 minutes of this time at an intensity level that corresponds to approximately $95 \%$ of their $\mathrm{VO}_{2} \max$. The first $11 / 2$ to 2 minutes of the race (at start) time the anaerobic energy system works maximally to provide the majority of the energy necessary to execute the race strategy. Of course, none of the energy systems work entirely alone, as there is 
always some interaction (Keul, J., 1973).

Judging by the intensity level of exercise, it is apparent that a high aerobic capacity complimented with a high ventilatory threshold would be most beneficial in racing 2,000 meters (Droghetti, 1986). The production and accumulation of lactate may be reduced (less) with a higher ventilatory threshold as compared to a low ventilatory threshold. This could ultimately reduce the detrimental effects of high lactates on performance (ie. early muscle fatigue). A high aerobic capacity is important because of the high percentage of absolute $\mathrm{VO}_{2} \max$. the oarswoman rows the majority of the race at. The present findings may provide athletes and coaches with a better understanding of the metabolic demands of the 2,000 meter race such that training regimens and racing strategies no longer have to be hypothetical guess work.

One of the most fascinating findings in this study is that all of the 6 athletes work outputs (as measured by the \# of flywheel revolutions) were far below that achieved in a standard rowing ergometer test. The standard test is 7 minutes in length and incorporates a loading of $2.5 \mathrm{kp}$ on the flywheel. This test is used to compare and evaluate oarswomen by giving them an absolute score in \# of revolutions. The pacing strategy of the standard test varies from that in a race or race simulation. In the standard test, the athlete executes a few short strokes ( 3 or 4) to get the flywheel spinning, and then immediately 
settles into a steady state output. During this test proceedure, feedback regarding flywheel revolutions is usually given verbally every 30 seconds. Oarswomen strive to maintain consistent splits throughout the test. In contrast, the race simulation or water race entails a fast sprint start lasting approximately 45 to 60 seconds. This sprint is followed by a settling (decreasein stroke rate increase in stroke length) into a steady state output. The finish of the race again involves the execution of a sprint for approximately 45 to 60 seconds. By recording the total number of flywheel revolutions in each race simulation, average minute splits were determined (table II). Relative to the oarswomen's standard rowing ergometer test splits, the race simulation splits were from 70 to 120 revolutions per minute lower. Reflecting on this discrepancy it could be hypothesized that the lower scores are a result of either lack of verbal feedback (regarding splits) during the race simulation, a result of poor racing strategy, or a combination of the two. It would be interesting to examine these two tests in an attempt to determine what the limiting factors of the race simulation are. An alteration in the on-water race strategy would be to approach the pacing as it is executed on the rowing ergometer. Rather than sprinting in the first minute of the race, a rapid settle into a steady state output could be implimented. Future research, comparing the physiological responses between the standard test and the race simulation 
approach may provide strong evidence in favour of a racing strategy adjustment.would definitely be beneficial to the oarswoman's racing performance. 
PROGRESSIVE INTENSITY TEST

INFORMED CONSENT FOR ELITE OARSWOMEN

You will perform a graded exercise test on the Dr. Gjessing rowing ergometer. The purpose of the test is to examine the response of your cardiovascular and respiratory systems to rowing. The test consists of rowing the ergometer for approximately 8 to 12 minutes during which time the loading on the flywheel will be progressively increased to a maximum of $2.5 \mathrm{kp}$.

During the test ventilatory gases will be recorded with the use of a mouthpiece, head gear, metabolic measurement cart and data acquisition system. Heart rates will be monitored with an ECG and blood samples made via cathaterization of the right arm cephalic vein (inserted and monitored by a medical doctor). Catheterization may cause some slight bruising the day following the test.

As the name of the test suggests, it is progressive. You will start the test with a loading of $1.25 \mathrm{kp}$. and pull hard enough to maintain a 300 revolution split every 30seconds. Each minute the load will be increased by $.25 \mathrm{kp}$. until $2.5 \mathrm{kp}$. is reached (maintaining the 300 rev/30sec splits throughout). After rowing for 1 minute at $2.5 \mathrm{kp}$., you will be required to increase your work output such that your revs. increase by 20 each minute following. 
You may row at what ever stroke rate you wish and alter it as you see fit.

The test will be discontinued when a plateau in your oxygen uptake values is reached (indicating maximum capacity), you cannot continue or your work output drops by a substantial margin. Following the completion of the test you will be required to remain seated on the ergometer with all testing gear attached so that recovery values may be collected (no cool down will be permitted until the data collection is completed).

At any time before or during the testing you may withdraw from this study if you are not pleased with what is taking place. Every effort will be made to ensure you do not experience any unnecessary discomfort. If you wish to ask any questions of the researcher and this study feel free to do so.

In signing this consent form you state that you have read and understand the description of the test and potential complications. You enter this test willingly and may with draw at any time.

\section{Consent}

I have read the above comments and understand the explanation, and I wish to proceed with the tests. In agreeing to such an examination, I waive any legal recourse against the members of the staff of the John M. Buchanan 
Exercise science Lab from any and all claims resulting from personal injuries sustained during these tests. date: subject (signature): witness: 
PROTOCOL AND CONSENT FORM

RACE SIMULATION (ROWING ERGOMETER 6:30 MIN. TEST)

The purpose of this test is to measure the amount of oxygen that you utilize while rowing in a simulated race. As well, the test will be used to measure the amount of lactic acid produced by the muscles during the simulation.

You will be given time to warm-up on the testing ergometer before the commencement of testing procedures. After you feel adequately warm a technician will tape 3 electrodes to your chest such that your heart rate can be recorded. At this time the, attending physician will insert the flexible catheter into the cephalic vein of your right arm. The vein will be kept open with the use of heparinized saline solution. There will be little discomfort associated with this procedure; there may, however be slight bruising at the point of the vein puncture.

Once you have remounted the ergometer a gas collection mouthpiece will be placed in your mouth and secured through the aid of head gear. The final required apparatus is a walkman which will be clipped to the back of your shorts.

The testing weight will be $2.5 \mathrm{kp}$ (standard testing weight). You will not receive any feedback as to revolutions or stroke rates. The only voice you will hear will be that of the coxswain on the tape recording. Blood 
samples will be drawn every minute during the exercise and for the 15 minutes of recovery.

It is expected that you will complete this test without complications. Because of the very common, unpredictable response of some individuals to exercise, unforeseen difficulties may arise which would necessitate treatment. Complications have been few during exercise tests amd these usually clear quickly with little or no treatment. You are asked to report any unusual symptoms during the testing procedures. You will be able to stop exercising at any time because of feelings of fatigue or discomfort. Every effort will be made to conduct the tests in such a way as to minimize discomfort and risk.

In signing this consent form you state that you have read and understand the description of tests, and the possible complications involved. You enter the testing procedures willingly, but may withdraw or refuse to participate at any time. Finally, all information collected about you will be kept in the strictest confidence.

CONSENT: I have read the above comments and understand the explanation which is given. I willingly enter into these testing procedures. DATE : 


\section{BIBLIOGRAPHY}

1) Asmussen, E.. Aerobic Recovery after Anaerobiosis in Rest and Work. Acta.Physiol.Scand. 11: 197-210 (1946).

2) Astrand, P.O. \& Saltin, B.. Oxygen uptake during first minutes of heavy muscular exercise. J. Appl. Physiol. No. 16. p971. 1961.

3) Astrand, P.O. \& Rodahl, K. Textbook of Work Physiology. McGraw-Hill Inc. 1977.(2nd edition).

4) Berger, R.A.. Applied Exercise Physiology - chapter 2: Energy for Muscular Endurance.Lea \& Febiger, Phil Philadelphia (1982)

5) Bouchaert, J.. Cardiorespiratory Responses to bicycle \& rowing ergometer exercise in oarsmen. Eur. J. Appl. Physiol. 51:51-59 (1983).

6) Brooks, G.A. \& Fahey, T.D.. Exercise Physiology Human Bioenergetics \& It's applications. John Wiley \& Sons Inc.. p.49\& 192 (1984).

7) Carey, P. et.al.. Comparison of oxygen uptake during work on the treadmill \& rowing ergometer. Med.Sci. sports. Vol.6. No.2. (1974).

8) CATCH, special issue, CELEBRATION -WOMEN IN ROWING (summer, 1984).

9) Cerretelli, P.. Oxygen Debt: Definition, Role \& Significance. Med.Sci.sports.Exer. Vol. 17. p68(1984).

10) Clark, et.al.. Breathing patterns during submaximal \& maximal exercise in elite oarsmen. J. Appl. Physiol. 55 (2) 440-446 (1983).

11) Cowan, C. \& Solandt,O.M.. The duration of the recovery period following strenuous muscular exercise, measured to a baseline of steady mild exercise. J. Physiol. 84: 462-466. (1937).

12) Cunningham, D.A., et.al.. Cardiorespiratory response to exercise on a rowing and bicycle ergometer. Med. Sci. sports. $7 \cdot 37-43 \cdot(1975)$.

13) Devries, H.A.. Physiology of Exercise for Physical Education \& Athletes. Wm. C. Brown Publishers (1974 \& 1986). 
14) Diprompero, P.B., et.al.. Physiological Aspects of Rowing. J.Appl. Physiol. Vol.31, No. 6 (1971).

15) Droghetti, P.. Determination of Anaerobic Threshold on a Rowing Ergometer by the relationship between work output and heart rate. Scand. J. Sports Sci. 8(2):59$62(1986)$.

16) Evans, B.W. \& Cureton, K.J.. Effects of Physical Conditioning on blood lactate disappearance after submaximal exercise. Brit. J. Sports Med.. Vol.17 No.1. p.40-45. March (1983)

17) Fiegenbaum, et.al.. Exercise specific medical examination of oarsmen \& cyclists for diagnosis of exercise efficiency. Int. J. of sports Medicine. Vol.4 (1983).

18) Fox, E.L.. Sports Physiology. W.B. Saunders Company. Philidelphia, London, Toronto. p54-80. (1979).

19) Gaesser \& Brooks, G.A.. Metabolic Bases of Excess PostExercise Oxygen Consumption: A Review. Med. Sci. Sports Exerc. 16:1. p.29 (1984).

20)Ganong, W.F.. Review of Medical Physiology. 4th ed. CV. Mosby Comp. (1981).

21)Gollnick, P.D. \& Hermansen, L.. Biochemical Adaptations to Exercise: Anaerobic Metabolism. In Wilmore,J.H. Exercise \& Sport Sciences Reviews. Vol.1. p.1-43. New York, Academic Press Inc. (1973).

22) Graham, T.E.. Oxygen Delivery \& Blood \& Muscle Lactate Changes During Muscular Activity. Can. J. Appl. Sport Sci.. Vol.3. No.4. p.155-160 (1971).

23) Hagerman, F.C.. A Comparison of Selected Physiological Variables Among Outstanding Competitive Oarsmen. I. Sports Med.. Vol.12. (1972).

24) " Applied Physiology of Rowing. Sports Med. 1:303-326. (1984).

25) " Teamwork in the Hardest Pull in sports. Phys. \& Sports Med.. 3-39. (1975).

26) " Physiological Profiles of Elite Rowers. Phys. \& Sports Med.. Vol.7. No.7. July (1979).

27) Hagerman, F.C. \& Lee, W.D.. Measurement of $\mathrm{VO}_{2}$, HR \& Work Output During Ergometer Rowing. Med. Sci. Sports Exerc.. Vol.3. No.4. p.155. (1971). 
28) Hagerman, F.C., et.al.. Metabolic Responses of Women Rowers During Ergometer Rowing. Med. Sci. Sports Exerc.. Vol.6. No.1. p 87. (1984) (abstract).

29) Hagerman, F.C., et.al.. Energy Expenditure During Simulated Rowing. J. Appl. Physiol. 45(1) p.87-93. (1978).

30) Hagerman, F.C., et.al.. Maximal oxygen consumption of conditioned \& unconditioned oarsmen. J. Sports Med.. $15: 43-48$. (1975).

31) Hagerman, F.C. \& Staron, R.S. Seasonal Variations Among Physiological Variables in Elite Oarsmen. Can. J. Appl.Sport Sci.. Vol.8 p.143-148. (1983).

32) Hermansen, L. et.al.. Post-exercise elevation of Resting $\mathrm{VO}_{2}$ : Possible Mechanisms \& Physiological Significance. Med. Sci. Sports Exerc.. Vol.17. p.119-129 (1984).

33) Holloszy, J.O.. Biochemical Adaptations to Exercise: Aerobic Metabolism. In Wilmore, J.H. (editors): Exercise \& Sport Sciences Reviews. Vol.1. p.1-43. New York Academic Press, Inc.. (1973).

34) Hebbelinck, M., et.al.. Anthropometric Characteristics of Female Olympic Rowers. Can. J. Appl. Spt. Sci.. $5: 4$. 255-262 . (1980).

35) Jackson, R.C. \& Secher, N.H.. Aerobic Demands of 2 Olympic Rowers. Med. Sci. Sports Exerc.. Vol.8. No.3. p.168-170. (1976).

36) Katch, V. \& Henry, F.M.. Prediction of running performance from maximal oxygen debt \& intake. Med. Sci. Spots Exerc.. Vol.4. No.4. p. 187. (1972).

37) Keele, C.A. et.al.. Respiration. In Samson Wrights Applied Physiology, 1.3th edition. Oxford University Press. (1982).

38) Keul, J.. The relationship between circulation \& metabolism during exercise. Med. Sci. in sports. Vol. 5. No.4. p.209-219. (1973).

39) Knuttgen, H.G.. Oxygen debt after submaximal Physical Exercise. J.Appl. Physiol..29(5). (1970).

40) Koutedakis, Y. \& Sharp, N.C.C. . Lactic Acid Removal \& Heart Rate Frequencies during Recovery After strenuous Rowing Exercise. Brit. J. Sports Med. Vol.19. No.4. 
p.199-202. (1985).

41) Levitzky, M.G. . Pulmonary Physiology. MCGraw Hill Inc.. Chapter 11. p.202-207. Chapter 9. p.187-189. (1982).

42) Mackenzie, D.C. \& Rhodes, E.C.. Cardiorespiratory \& Metabolic Responses to Exercise on a Rowing Ergometer. Aust. J. Sports Med. Vol.14. No.1. (1982).

43) Mahler, D.H., et.al.. Comparison of 6-min All-out \& Incremental Exercise Tests in Elite Oarsmen. Med. Sci. Sports Exerc. Vol.16. No.6. p.567-571. (1984).

$44)$ Mahler, D.H., et.al.. Physiologic Changes in Rowing Performance associated with training in collegiate women rowers. Int. J. Sports Med.. 6. p.229-233. (1985).

45) Mahler, D.H., et.al.. Comparison of Exercise Performance on Rowing \& Cycle Ergometers. Research Quarterly for Exercise \& Sport. Vol.58. No.1. p.4146. (1987).

46) Margaria, R., et.al.. Kinetics \& Mechanisms of oxygen debt contraction in man. J. Appl. Physiol.. 18(2). p.371-377. (1963).

47) Margaria, R. et.al.. The Possible Mechanisms of contracting and paying the oxygen debt \& the role of lactic acid in muscular contraction. Am. $\mathrm{J}$. Physiol.. 18(2). p.371-377. (1963).

48) Mickelson, T.C. \& Hagerman, F.C.. Anaerobic Threshold Measurements of Elite Oarsmen. Med. Sci. Sports Exerc., Vol.14. No.6. (1982).

49) Mole, A.A.. Exercise Metabolism. In Exercise Medicine Pysiological Principles \& Clinical Applications. Bove, A.A. \& Lowenthal, D.J.. Academic Press Inc.. (1983).

50) Rosiello, R.A., et.al.. Cardiovascular responses to rowing. Med. Sci. Sports Exer.. Vol.19. No.3. p.239245. (1987).

51) Secher, N.H.. The physiology of rowing. J. of Sports Sciences. Vol. 1:23-53. (1983)a.

52) " Maximal Aerobic Power in Oarsmen. Eur. J. Appl.Physiol.. 51:155-162 . (1983) b.

53) Secher, N.H., et.al.. Rowing Performance \& Maximal Aerobic Power of Oarsmen. Scand. J. Sports Sci. $4(1)$. p.9-11. (1982)a. 
54) Secher, N.H., et.al.. Aerobic Rower at onset maximal exercise. Scand. J. Sports Sci.. 4(1). p.12-16. $(1982) \mathrm{b}$.

55) Sjodin, B., et.al.. The Physiological Background of Onset of Blood Lactate Accumulation (OBLA). Exercise \& Sport Biology, International series on sport sciences Vol. 12. edited by Komi, P.V.. p.43. (1979).

56) Slonim, N.B. \& Hamilton, L.H. . Respiratory Physiology. 4th edition. CV Mosby Corp.. (1971).

57) Stainsby, W.N. \& Barclay, J.K.. Exercise Metabolism: $\mathrm{O}_{2}$ deficit, steady level $\mathrm{O}_{2}$ uptake \& $\mathrm{O}_{2}$ uptake for recovery. Med. Sci. Sport. Vol.2. No.4. p.177-182 (1970).

58) Steinacker, J.M., et.al.. oxygen consumption \& metabolic strain in rowing ergometer exercise. Eur. J. Appl. Physiol. 55: 240-247. (1986)

59) Stromme, et.al.. Assessment of maximal aerobic power in specifically trained athletes. I. Appl. physiol.. 42: 833-837. (1977).

60) Szogy, A. \& Cherebetiv, G..Physical work capacity testing in male performance rowers with practical conclusions for their training process. J. of sports Med.. Vol.14. p.218. (1974).

61) Thaden,J.S.,et.al.. Physiological Testing of Elite Athletes (C.A.S.S.). Chapter 4: Testing Aerobic Power. MacDougall, Wenger, \& Green (editors). (1982).

62) Volkov, N.I.. Assessment of Aerobic \& Anaerobic Capacity of Athletes in Treadmill Running Tests. Eur. J. Appl. Physiol.. 34:121-130. (1975).

63) Wasserman, K., et.al.. Mechanisms \& Patterns of blood lactate increase during exercise in man. Med. Sci. Sport. Vol.18. No.3. p.344-352. (1986).

64) Wasserman, K., et.al.. Anaerobic Threshold \& Respiratory Gas Exchange During Exercise. J. Appl. Physiol.. Vol.35. No.2. August (1973).

65)Wasserman, K., et.al.. Breathing During Exercise. New England Journal of Medicine. Vol.298. No.14. April (1978).

66) Welch, H.G., et.al.. Ventilatory Response during Recovery from Muscular Work \& its Relation with $\mathrm{O}_{2}$ Debt. Med. Sci. Sport. Vol.2. No.1. p.15-19. (1970). 
67) Whipp, B.J., et.al.. oxygen deficit-oxygen debt relationship and efficiency of anaerobic work. J. Appl. Physiol.. 28(4): 452-456. (1970).

68)Williams, L.R.T.. Work Output \& Heart Rate Response of Top Level New Zealand Oarsmen. Research Quarterly. Vol.47. No.3. p.506-512. (1976).

69) Wilmore, J.H..The Application of Science to sport: Physiological Profiles of Male and Female Athletes. Can. J. Appl. Spt. Sci.. 4:103. (1979).

70) Young, I.V. \& Rhodes, T.E.. Energy Demands of 2,000 meter Rowing Race for Collegiate Oarswomen. Med. Sci. Sport Exer.. Vol.11. No.4.(1986).(abstract). 
APPENDIX A PROGRESSIVE INTENSITY TEST PROTOCOL

\begin{tabular}{lll}
\hline $\begin{array}{l}\text { TIME } \\
\text { (min) }\end{array}$ & $\begin{array}{l}\text { LOAD } \\
(\mathrm{kp})\end{array}$ & $\begin{array}{l}\text { REVOLUTION } \\
\text { (revs/min) }\end{array}$ \\
$0-1$ & 1.25 & 600 \\
$1-2$ & 1.5 & 600 \\
$2-3$ & 1.75 & 600 \\
$3-4$ & 2.0 & 600 \\
$4-5$ & 2.25 & 600 \\
$5-6$ & 2.50 & 600 \\
$6-7$ & 2.50 & 620 \\
$7-8$ & 2.50 & 640 \\
$8-9$ & 2.50 & 660 \\
$9-10$ & 2.50 & 680 \\
etc. & & \\
\hline
\end{tabular}




\section{APPENDIX B}

EXERCISE METABOLISM CALCULATIONS
RESTING $\mathrm{VO}_{2}=$ mean $\mathrm{VO}_{2}$ as measured during the resting period prior to RS

DEVRIES (1986) (pg. 221)

1) TOTAL GROSS $\mathrm{O}_{2}$ COST $=\mathrm{O}_{2}$ EXERCISE $+\mathrm{O}_{2}$ RECOVERY

2) TOTAL NET $\mathrm{O}_{2} \operatorname{COST}=\mathrm{O}_{2}$ EXERCISE + $\mathrm{O}_{2}$ RECOVERY [ $\mathrm{VO}_{2}$ for equal rest period]

3) $\mathrm{NET} \mathrm{O}_{2}$ COST PER MIN. EXERCISE $=\frac{\text { TOTAL NET O }}{\text { EXERCISE TIME }} \frac{\operatorname{COST}}{\mathrm{i}}$

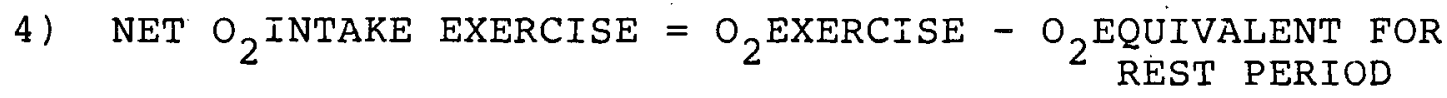

5) NET $O_{2}$ INTAKE EXERCISE(PER MIN.) = NET O INTAKE

6) "O ${ }_{2}$ DEBT" INCURRED PER MIN. = NET $\mathrm{O}_{2}$ COST PER MIN. OF EXERCISE $\underline{2}$ NET O INTAKE EXERCISE PER ${ }^{2}$ MIN.

7) TOTAL "O ${ }_{2}$ DEBT" INCURRED = EXERCISE TIME $\times \mathrm{O}_{2}$ DEBT PER EXCESS POST-EXERCISE $\mathrm{VO}_{2}$ $=$ Recovery $\mathrm{VO}_{2}$ minus $\mathrm{VO}_{2}$ for equal period of rest 


\section{APPENDIX C}

TABLE II CALCULATIONS

EXERCISE $\mathrm{VO}_{2}$

$$
\begin{aligned}
\mathrm{X} & =117.45 / 6 \\
& =19.56 \mathrm{~L} \\
\mathrm{~s} & =\sqrt{\frac{\mathrm{ETX}-\mathrm{X})}{\mathrm{n}-1}}=\sqrt{\frac{6.4049}{5}}= \pm 1.13 \mathrm{~L}
\end{aligned}
$$

RECOVERY $\mathrm{VO}_{2}$

$$
\begin{aligned}
& \mathrm{X}=\frac{29.49}{6}=4.92 \mathrm{~L} \\
& \mathrm{~s}=\sqrt{\frac{1.2403}{5}}= \pm 0.498 \mathrm{~L}
\end{aligned}
$$

TOTAL $\mathrm{VO}_{2}$

$$
\begin{aligned}
& \bar{x}=\frac{146.94}{6}=24.48 \mathrm{~L} \\
& s=\sqrt{\frac{10.2417}{5}}= \pm 1.43 \mathrm{~L}
\end{aligned}
$$

RESTING $\mathrm{VO}_{2}$

$$
\overline{\mathrm{X}}=0.42 \mathrm{~L}
$$

$$
s=\sqrt{\frac{0.01 / 2}{5}}= \pm 0.06 \mathrm{~L}
$$




\section{APPENDIX D}

\section{MATCHED PAIRS̀ T-TESTS:}

$(\mathrm{df}=5,0.01)$

FORMULA USED

$$
\begin{aligned}
& \bar{D}=\text { sum of } D / n \text { s } s_{D}=s q \cdot \text { root }\left\{D^{2}-(\text { sum of } D)^{2} / n\right\} / n(n-1) \\
& S_{\bar{D}}=S_{D} / s q \cdot \text { root of } n \\
& t=\bar{D} / S_{\bar{D}}
\end{aligned}
$$

EXCESS $\mathrm{CO}_{2} \quad \mathrm{~S}_{\mathrm{D}}=0.56$

$$
\begin{aligned}
& s_{\bar{D}}=0.23 \\
& t^{\prime}=17.65 \quad(p<.01)
\end{aligned}
$$

$\mathrm{VO}_{2} \mathrm{MAX}$

$$
\begin{aligned}
S_{D} & =0.05 \\
S_{\bar{D}} & =0.021 \\
t & =2.59 \quad(p>0.01)
\end{aligned}
$$

$\mathrm{MAX} \cdot \mathrm{V}_{\mathrm{E}} \cdot$

$$
\begin{aligned}
s_{D} & =1.7 \\
S_{\bar{D}} & =0.695 \\
t & =10.86 \quad(p<.01)
\end{aligned}
$$

MAX.HR

$$
\begin{aligned}
& S_{D}=1.66 \\
& S_{\bar{D}}=-0.68 \\
& t=-0.25 \quad(p>.01)
\end{aligned}
$$

